\title{
What do we know about the ecotoxicological implications of the rare earth element gadolinium in aquatic ecosystems?
}

\author{
Giacomo Trapasso ${ }^{\text {a }}$, Stefania Chiesa ${ }^{\mathrm{a}, \mathrm{b}}$, Rosa Freitas ${ }^{\mathrm{c}, *}$, Eduarda Pereira ${ }^{\mathrm{d}}$ \\ a Department of Molecular Sciences and Nanosystems, Ca' Foscari University of Venice, Italy \\ b ISPRA, The Italian Institute for Environmental Protection and Research, Rome, Italy \\ ' Departamento de Biologia \&' CESAM, Universidade de Aveiro, Portugal \\ ' Departamento de Química E REQUIMTE, Universidade de Aveiro, Portugal
}

\section{H I G H L I G H T S}

- More research on gadolinium (Gd) occurrence in freshwater than marine environments

- Few publications on the accumulation and effects of Gd in aquatic invertebrates

- Higher diversity of freshwater species than marine species in Gd impacts studies.

- Aquatic invertebrates differently bioaccumulate Gd according to its speciation.

- Gd causes alterations at different biological levels in aquatic invertebrates.

\section{A R T I C L E I N F O}

\section{Article history:}

Received 5 November 2020

Received in revised form 4 February 2021

Accepted 28 February 2021

Available online 8 March 2021

Editor: Elena Paoletti

\section{Keywords:}

Emerging pollutants

Gadolinium

Metal speciation

Bioaccumulation

Biomarkers

Aquatic invertebrates
G R A P H I C A L A B S T R A C T

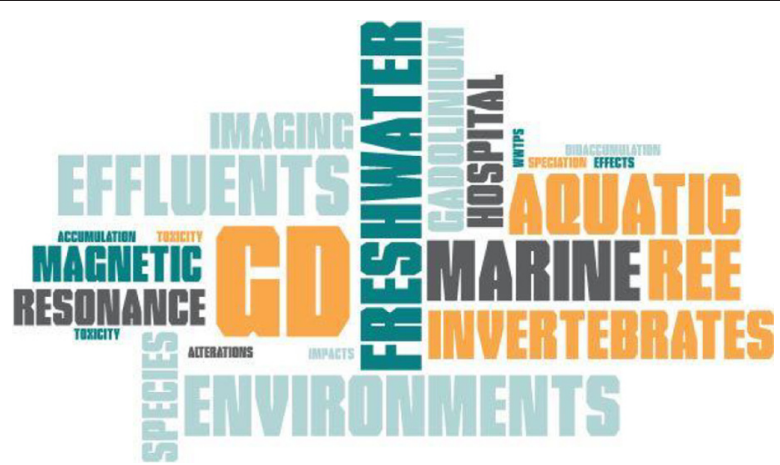

\section{A B S T R A C T}

Gadolinium (Gd) is one of the most commercially exploited rare earth elements, commonly employed in magnetic resonance imaging as a contrast agent. The present review was performed aiming to identify the Gd concentrations in marine and freshwater environments. In addition, information on Gd speciation in the environment is discussed, in order to understand how each chemical form affects its fate in the environment. Biological responses caused by Gd exposure and its bioaccumulation in different aquatic invertebrates are also discussed. This review was devoted to aquatic invertebrates, since this group of organisms includes species widely used as bioindicators of pollution and they represent important resources for human socio-economic development, as edible seafood, fishing baits and providing food resources for other species. From the literature, most of the published data are focused on freshwater environments, revealing concentrations from 0.347 to $80 \mu \mathrm{g} / \mathrm{L}$, with the highest Gd anomalies found close to highly industrialized areas. In marine environments, the published studies identified a range of concentrations between 0.36 and $26.9 \mathrm{ng} / \mathrm{L} \mathrm{(2.3} \mathrm{and} 171.4 \mathrm{pmol} / \mathrm{kg}$ ), reaching $409.4 \mathrm{ng} / \mathrm{L}(2605 \mathrm{pmol} / \mathrm{kg}$ ) at a submarine outfall. Concerning the bioaccumulation and effects of $\mathrm{Gd}$ in aquatic species, most of the literature regards to freshwater species, revealing concentration ranging from 0.006 to $0.223 \mu \mathrm{g} / \mathrm{g}$, with high variability in the bioaccumulation extent according to Gd complexes chemical speciation. Conversely, no field data concerning Gd bioaccumulation in tissues of marine species have been published. Finally, impacts of Gd in invertebrate aquatic species were identified at different biological levels, including alterations on gene expression, cellular homeostasis, shell formation, metabolic capacity and antioxidant mechanisms. The information here presented highlights that Gd may represent an environmental threat and a risk to human health, demonstrating the need for further research on Gd toxicity towards aquatic wildlife and the necessity for new water remediation strategies.

(c) 2021 Elsevier B.V. All rights reserved.

\footnotetext{
* Corresponding author.

E-mail address: rosafreitas@ua.pt (R. Freitas).
} 


\section{Introduction}

\subsection{Rare earth elements}

The International Union for Pure and Applied Chemistry (IUPAC) has included the following definition of rare earth elements (REEs): a group of 17 elements, similar from physical and chemical point of view. Rare earth elements include scandium (Sc), yttrium (Y) plus 15 lanthanides, namely lanthanum (La), cerium (Ce), praseodymium (Pr), neodymium $(\mathrm{Nd})$, promethium $(\mathrm{Pm})$, samarium $(\mathrm{Sm})$, europium $(\mathrm{Eu})$, gadolinium (Gd), terbium ( Tb), dysprosium (Dy), holmium (Ho), erbium (Er), thulium (Tm), ytterbium (Yb), and lutetium (Lu) (Gwenzi et al., 2018; IUPAC, 2005). These elements are less than $20 \%$ of all elements naturally occurring in the environment (Klinger, 2015). This general classification given by IUPAC identifies two groups of lanthanides: light rare earths (LRE - from La to Eu) and heavy rare earths (HRE - from Gd to Lu and Y) (IUPAC, 2005). Scandium represents the lightest REE, being quite different from both LREEs and HREEs, thus, it is not included in these two groups (Atwood, 2012). The above-mentioned classification is based on the electron configuration of each element (electron filling of the $4 f$ orbitals), which affects their behaviour with other compounds. Another classification, majorly used in mineral extraction terminology, divides REEs in three groups: light REEs ( La, Ce, Pr, Nd and Pm), medium REEs (Sm, Eu and Gd) and heavy REEs (Tb, Dy, Ho, Er, Tm, Yb, Lu, Sc and Y), according to their ionic radii (Nakamura et al., 1997; Australian Industry Commission, 1995). Since REEs can both form complexes with many ions (phosphate, hydroxide, fluoride, carbonate and silicate) and be sorbed to organic matter and clay (Sneller et al., 2000), their solubility can vary in freshwater and in seawater, according to pH (Kálmán et al., 2007; Wang et al., 1992), temperature, concentration (Sherry et al., 2009a, 2009b), salinity and concentration of the abovementioned negative counter ions (Sneller et al., 2000). For these reasons, there is no common accepted classification regarding the assignment of each lanthanide to one group or another. However, in this review, the IUPAC notation will be used.

Rare earth elements are widely distributed in the Earth's crust in average concentrations ranging from 150 to $220 \mathrm{mg} / \mathrm{kg}$ (Kamenopoulos et al., 2016). The "rare" definition does not reflect their abundance in the environment, which is higher than those of gold or copper, but the form in which they occur, dispersed in ores instead of in the native form of aggregates or nuggets (as for example gold or copper) (Goodenough et al., 2016; Zepf, 2015). Even if the global REEs reserves were estimated to be around 130,000 t in 2016 (USGS, 2016; Massari and Ruberti, 2013), the supply of these elements is limited to a small number of mining fields (Chakhmouradlan and Wall, 2012). The largest mines are situated in Asia (Mancheri et al., 2019), with China representing the country where REEs reserves are most abundant (Shen et al., 2017; Zhou et al., 2016). Moreover, China developed leading processing technologies and production facilities for REEs exploitation, resulting in REEs production of about 120,000 t/year, more than $90 \%$ of the global production, which reached the $97 \%$ in 2010 (Mancheri et al., 2019; USGS, 2010; Zhou et al., 2016).

The unique properties of REEs, such as ideal magnetic behaviour and sharply defined energy states, made them a strategic resource in nowadays economy (Migaszewski and Gałuszka, 2015). In fact, REEs are important components in different industrial sectors, from traditional (lighter, flints, fluorescent lamps), to high-tech (batteries, lasers, super-magnets) and novel ones (high-temperature superconductivity, information storage, conservation and transport of energy) (Anastopoulos et al., 2016). In addition, they represent key elements (or components) of updated technologies, with particular reference to the protection of environment, medical applications, nuclear industry and digital technology. Moreover, they are a valuable and relevant component of many electronic devices, employed as magnets, catalysts, superconductors, medical and agricultural products (US-EPA, 2012; Li et al., 2013; Zhang et al., 2014; Zhang et al., 2015).
The wide use of REEs in numerous industrial fields enhances the risk for these elements to potentially reach the freshwater and marine environments (Khan et al., 2017), thus increasing the possible threats to these systems and, in particular, to inhabiting wildlife. The increased REEs levels observed in aquatic environments was revealed for the first time, among others, by Bau and Dulski (1996), who described a positive correlation between gadolinium (Gd) concentrations and freshwater inputs from areas with higher occurrence of industrial plants. Therefore, the occurrence of REEs in the aquatic ecosystems is expected, in particular through domestic wastewater and industrial effluents, surface run-off and atmospheric deposition (Hatje et al., 2016; Kulaksız and Bau, 2011). As a result of this increasing contamination, REEs are currently considered as "emerging contaminants", however the knowledge about their impacts towards freshwater and marine biota is still limited. In particular, a better understanding of their biogeochemical behaviour and toxicological effects is required, due to the scarce information regarding the responses of freshwater and especially marine species to REEs.

Gadolinium is considered one of the most abundant REEs in the earth surface (Greenwood et al., 1997) and, due to its peculiar proprieties, since 1980s it has been widely employed in various fields, particularly in the biomedical applications, such as in magnetic resonance imaging (MRI) due to its usefulness as a contrast agent. The use of Gd in MRI diagnostics significantly increased in the last two decades (Runge, 2018; Telgmann et al., 2013). For these reasons, understanding the possible effects of this element, especially in the aquatic ecosystems where it is most likely to be discharged, it is of paramount relevance for future technology development and to ensure the environmental safety.

\subsection{Gadolinium: main properties and applications}

Gadolinium is a soft, shiny, ductile, silvery metal which belongs to the lanthanide group within the chemical periodic table (Hron et al., 2009). Differently from the other REEs, in dry air Gd is relatively stable. However, it is oxidized promptly in moist air originating a black and thin film of $\mathrm{Gd}_{2} \mathrm{O}_{3}$ on its surface. Moreover, Gd slowly reacts with water and its complexes are typically dissolved in acids. For this reason, Gd is usually found in dissolved form, while other REEs of anthropogenic origin (such as La and Sm) occur in the form of colloid or nanoparticulates, according to the $\mathrm{pH}$, temperature and to the types of ligands involved (Gwenzi et al., 2018). In addition, Gd is the only lanthanide that has a ferromagnetic behaviour near room temperature, but above $293 \mathrm{~K}$ (Curie point $-\mathrm{T}_{\mathrm{c}}$ ) the element becomes a very strong paramagnet (Dan'kov et al., 1998).

In the Earth's crust, Gd presents a concentration of approximately $6.2 \mathrm{mg} / \mathrm{kg}$ (Gravina et al., 2018). However, it does not occur as a free element form but, in nature, it is included in different mineral components (i.e. bastnasite, laterite clays, monazite, and loparite) (Pecharsky and Gschneidner Jr., 2019). The most important and extensive mines for Gd exploitation are located in China, USA, Brazil, Greenland, India, and Tanzania, with estimated reserves exceeding 1,000,000 t (Emsley, 2011; Rogowska et al., 2018).

Gadolinium finds its major employment in the medical field (Telgmann et al., 2013), but it is also used in different industrial applications, such as control rods for nuclear plants (reactors and nuclear power), microwave garnets and colour TV tubes phosphorous components. Metallic Gd alloys are generally used for manufacturing magnets and electronic components, including video recorders parts such as the recording heads in compact disks and in computer memory (Rogowska et al., 2018). On the opposite, Gd it is barely employed as a metal (Rogowska et al., 2018).

The wide usage of Gd opened a debate and raised concerns about its contamination into the environment. In Germany, in 2013, it was reported that ca. $12 \mathrm{t} \mathrm{Gd}$ per year were used for biomedical purposes, being released via sewage systems into the environment (Cyris, 2013). Although diagnostic forms of Gd (used as contrast agents) are not 
toxic to biota, the processing treatments in the wastewater plants, can determinate modifications of Gd complexes and consequently toxic compounds may be released in the aquatic environments (Cyris, 2013).

\subsubsection{Chelates of gadolinium as contrast agents in magnetic resonance imaging}

Gadolinium proprieties, highlighted previously, made this element the first and the most often employed contrast agent to generate magnetic resonance images since the 1980 s, due to its highly paramagnetic proprieties (Runge, 2018; Telgmann et al., 2013).

The contrast agents which contain $\mathrm{Gd}$, used for magnetic resonance imaging (MRI), are aqueous solutions allowing the detailed observations of organs, thus improving quality of the images and more detailed pictures to be analysed (Raju et al., 2010). For this purpose, Gd ions are bound to other molecules, in order to decrease or even nullify their toxicity, however maintaining the water-solubility characteristics. This process is called chelation. Chelating agents can be either made by linear or macrocyclic molecules (Fig. 1). Macrocyclic chelates are more stable than the linear ones. Linear chelates can be classified into 2 groups: non-ionic and ionic, the latter group less stable from a thermodynamic point of view (Runge, 2018). Nevertheless, even if in most of the cases the complexation of the Gd ion reduces dramatically its toxicity, Kummerer and Helmers (2000) stated that Gd concentration in MRI patients' urine may reach $350 \mathrm{mg} / \mathrm{L}$ daily after the diagnostic treatment and $7 \mathrm{mg} / \mathrm{L}$ even after 39 days. These concentrations may cause the appearance of severe diseases, such as nephrogenic systemic fibrosis (NSF) as well as accumulation in patients' brain, bones and kidneys (Idee et al., 2006). Pathological effects have been documented through histological examination, particularly regarding diffuse ulcerative calcific atherosclerosis, patchy myocardial necrosis and fibrosis, central venous congestion of the liver as well as calciphylaxis and necrotic skin (Clases et al., 2018). For patients with a median age of 55 years, an average time of 112 days between the diagnosis of NSF and death have been reported (Clases et al., 2018). Nephrogenic systemic fibrosis causes characteristic symptoms, as skin thickening and hardening. This disease has been associated prior to the administration of Gd chelates, with higher incidence in those patients already suffering from renal inefficiency (Grobner and Prischl, 2007; Mendichovszky et al., 2008). Although these symptoms are observed only in cases with chronic or acute kidney failure, it has been described that in most cases, the Gd complexes administration with linear ligands led to NSF (Bellin and
Van Der Molen, 2008; Thomsen and Marckmann, 2008). However, it must be remarked that only few numbers of NSF cases have been tracked back to Gd complexes administration. Therefore, the pathogenesis of NSF due to these compounds can be considered as unclear (Telgmann et al., 2013). Due to these findings, further analytical methods for the detection of this metal in the organism and in the environment must be developed (Telgmann et al., 2013). All these Gdchelated compounds are dispensed in oral or intravenous form, at $0.12 \mathrm{mmol} \mathrm{Gd} \mathrm{complex} \mathrm{per} \mathrm{kg}$ of body weight, corresponding roughly to $1.2 \mathrm{~g}$ of $\mathrm{Gd} /$ person (considering $65 \mathrm{~kg}$ as an average body mass) (Möller et al., 2003). It is noteworthy to observe that recent estimations quantify $25-30 \%$ of all MRI investigations to be performed with contrast agents, accounting for 20 million applications per year worldwide (Cyris, 2013). Clinical studies showed that within few hours from the treatment, Gd complexes are excreted in non-metabolised form. After excretion, Gd complexes are therefore destinated to sewage system of hospital units, reaching surface and river waters (Raju et al., 2010).

\subsubsection{Gadolinium complexes dechelation process}

A possible reason for the toxicity of Gd complexes could relay in the mechanism involved in the dechelation process. This process causes the specific release of the Gd ion, which can exist in vivo, with the less stable complexing agents. In living organisms, only $\mathrm{Zn}^{2+}$ can replace a significant amount of $\mathrm{Gd}^{3+}$ due to its relatively abundant concentration in blood (between 55 and $125 \mathrm{mmol} / \mathrm{L}$ ). In addition, $\mathrm{Zn}^{2+}$ affinity towards ethylendiaminetetraacetic acid (EDTA), pentetic acid (DTPA) and tetraxetan (DOTA), employed as chelating ligands in most of the Gdbased magnetic resonance imaging (MRI) contrast agents, is only 4 magnitude orders lower than that of the ion $\mathrm{Gd}^{3+}$. This process is called transmetallation (Laurent et al., 2010; Runge, 2018). There are some other possible competitors, but they can be mostly ignored: copper ions are occurring but with low concentrations (1-10 mmol/L), calcium ions present a low affinity constant to organic ligands and iron ions are not available for transmetallation since they are strongly bound to ferritin and haemoglobin. Consequently, the Gd complexes stability depends also on the occurrence of $\mathrm{Zn}^{2+}$. Transmetallation process determinates the release of $\mathrm{Gd}$ cations and a possible depletion of the endogenous zinc ion following its renal elimination as a hydrophilic complex (Laurent et al., 2010). Recently, more attention has been placed on the process above described, due to increasing safety issues regarding the least stable gadolinium-based contrast agents (GBCAs) (Runge, 2018).

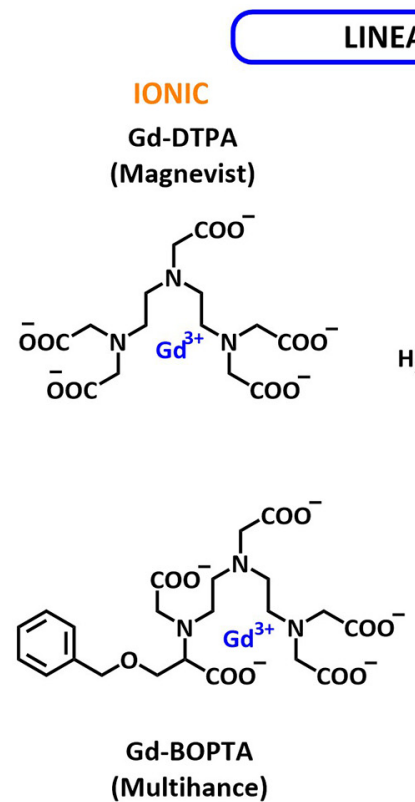

Gd-BOPTA
(Multihance)

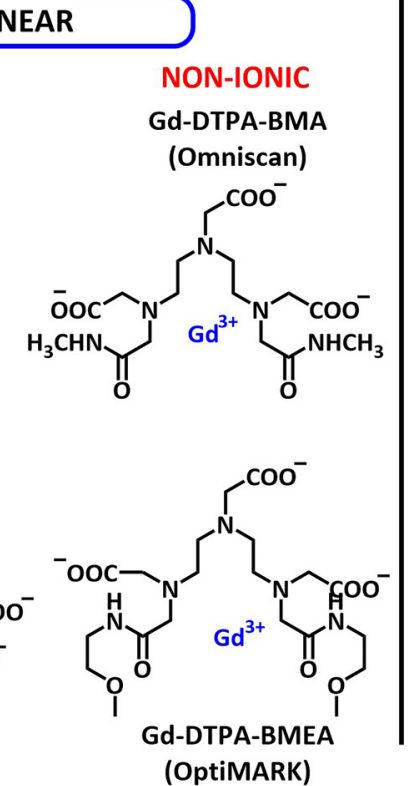

\section{MACROCYCLIC}

\section{IONIC}

Gd-DOTA

(Dotarem)

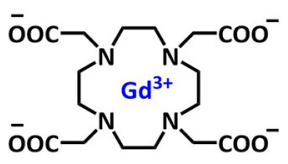

NON-IONIC

Gd-BT-DO3A

(Gadovist)

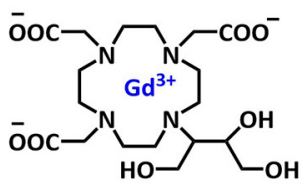

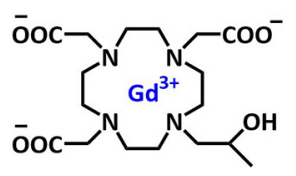

Gd-HP-DO3A

(ProHance)

Fig. 1. Chemical structure of seven of the most common Gd-based MRI contrast agents and their respective trademarks. 
The overall mechanism of Gd toxicity is based on the bond formed between metal cation and negatively charged chemical groups, especially present in biological systems (namely some aminoacids). Such coordination causes a malfunctioning of the cell membrane and/or of the enzyme activity (Rogowska et al., 2018). In fact, $\mathrm{Gd}^{3+}$ cation presents an ionic radius of $107.8 \mathrm{pm}$, which closely resembles the one of $\mathrm{Ca}^{2+}$ (114 pm) (Sherry et al., 2009a, b). Due to this similarity, free Gd behaves as an inorganic blocker of many types of voltage-gated $\mathrm{Ca}^{2+}$ channels at nano- to micro-molar concentrations. In addition, it inhibits physiological processes depending on $\mathrm{Ca}^{2+}$ influx (causing lack of smooth, skeletal and cardiac muscle contraction, transmission of nervous influx or blood coagulation) as well as the activity of some enzymes. Nevertheless, chelation of $\mathrm{Gd}^{3+}$ with suitable ligands reduces dramatically its acute toxicity (Bellin and Van Der Molen, 2008; Rogowska et al., 2018).

As mentioned previously, Gd employment in medical and technological field started relatively late, around 1980s, with a pronounced increase in its use only in the last two decades. For this reason, scarce literature exists on this topic and consequently few studies have been performed on the behaviour that this pollutant can have in the environment and inhabiting wildlife. Nevertheless, an increasing number of researchers has focused their attention on the possible toxic effects of this metal and its derivatives, performing both laboratory and in-situ studies.

\subsection{Bibliographic search performed and paper selection}

For the present article, the bibliographic search was conducted exploiting WoS (Web of Science), Google Scholar, Scopus and PubMed databases, choosing years from 1980s up to June 2020, with selected topics and/or keywords: "gadolinium effects on marine and freshwater invertebrates" and "gadolinium environmental effects" combined with (a) "biochemical effects"; (b) "bioaccumulation patterns"; (c) "biomarkers"; (d) "gene regulation" and (e) "uptake". The bibliographic search has been focused on bioaccumulation as well as on the analysis of biological effects of Gd on aquatic invertebrate species, since they are particularly exposed to environmental contamination.

Fig. 2 reports the schematic flow chart (modified from Chiesa et al., 2019) illustrating the logical framework of the bibliographic research from available literature. From this search, 132 scientific papers were obtained, comprising data from various marine and freshwater environments worldwide and several invertebrate species.

\section{Gadolinium in aquatic environments}

\subsection{Analytical methods for gadolinium quantification}

Concentrations of Gd in water solutions might be determined by spectrometric techniques, namely atomic absorption spectrometry (AAS) (Grobenski, 1978; Kimura et al., 2005; Lian et al., 1991), X-ray fluorescence (XRF) (Telgmann et al., 2011; Silva et al., 2020), inductively coupled plasma atomic emission spectrometry (ICP-AES) and inductively coupled plasma mass spectrometry (ICP-MS) but also chromatographic techniques like hydrophilic interaction liquid chromatography (HILIC) (Raju et al., 2010; Telgmann et al., 2013).

Atomic absorption spectrometry (AAS) and Graphite Furnace Atomic Absorption Spectrometry (GFAAS) can be used to quantify Gd regardless the complexes (namely Gd-DOTA, Gd-DTPA-BMA and GdDTPA) both in water solutions (Grobenski, 1978) and in biological materials like blood, urine and tissues (Kimura et al., 2005; Lian et al., 1991). Nevertheless, these techniques are scarcely employed in

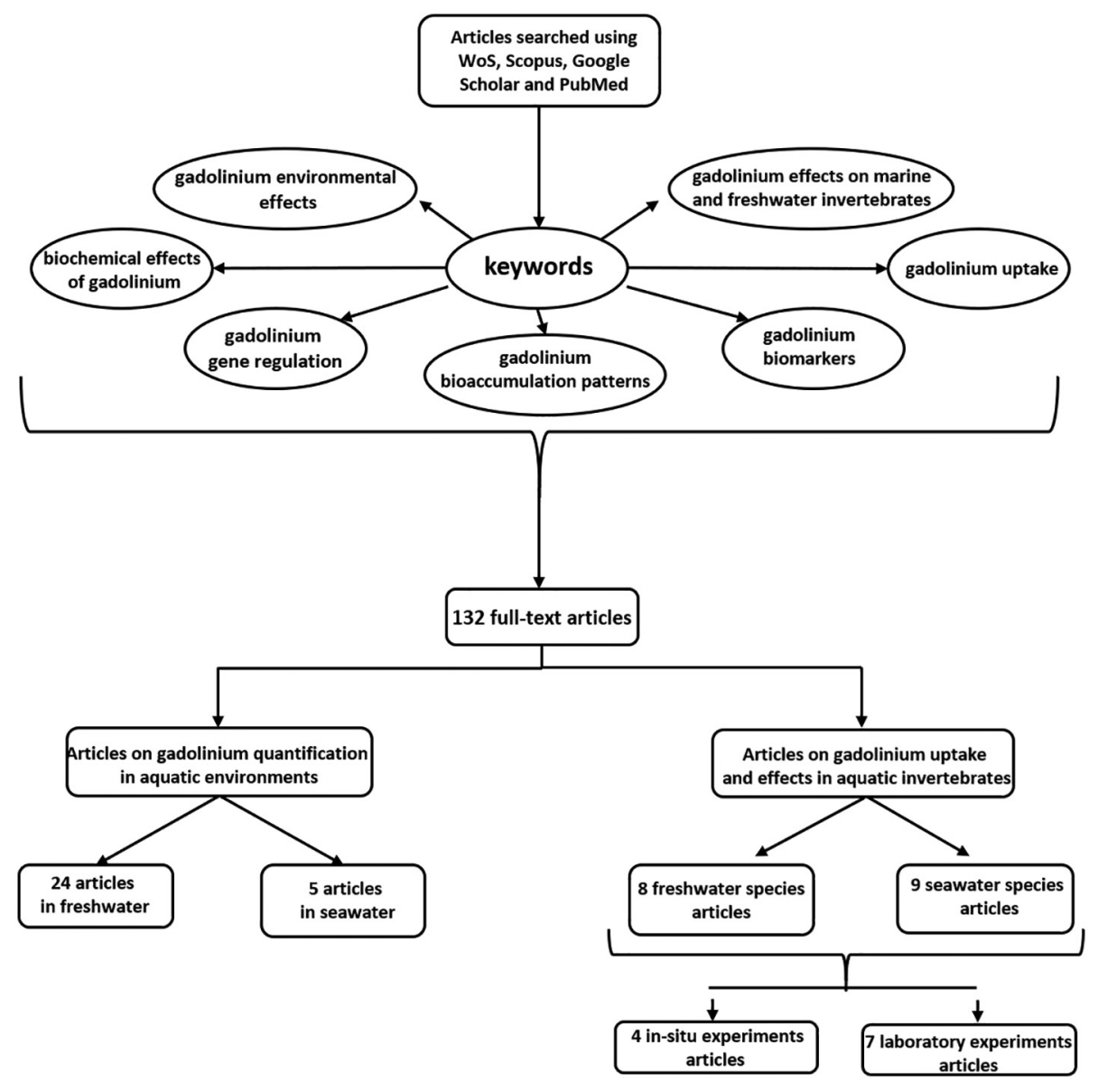

Fig. 2. Schematic flow diagram presenting the pipeline used for literature revision. 
literature mainly due to their low sensitivity, normally attributed to the formation of side products (i.e. refractory carbides and pyrocarbon shells) which cause noteworthy interferences during measurements (Lian et al., 1991).

Another technique employed for Gd detection is X-ray fluorescence and its derivatives: Total reflection X-ray fluorescence - TXRF and wavelength dispersive X-ray fluorescence - WDXRF. The former technique has been used by Telgmann and co-authors in 2011 to determine Gd concentration in human blood and urine, with a limit of detection (LOD) ranging from 80 to $100 \mu \mathrm{g} / \mathrm{L}$ and a limit of quantification (LOQ) from 270 to $330 \mu \mathrm{g} / \mathrm{L}$ (Telgmann et al., 2011). Instead, this method can be employed for the identification and analysis of geological materials containing metallic elements of high economic value, among which REEs and particularly Gd (Silva et al., 2020). However, it must be mentioned that relevant matrix effects and spectral interferences (particularly with $\mathrm{Gd}$ in the presence of $\mathrm{Nd}$ ), due to absorption and emission phenomena coming from other compounds in the sample, are also occurring during the process. This can cause a deviation from the linear relation between the intensity of the signal and the concentration of the REE, that can only be adjusted with the support of a mathematical model (Rousseau, 2006; Silva et al., 2020). XRF methods are fast and might be used universally for a huge diversity of samples containing metals atoms, which must have an atomic number greater than 11 . Due to its characteristics, this detection methodology has a key role in the industrial production of materials, in prospecting mineral resources and also in environmental monitoring (Klockenkämper and Von Bohlen, 2015).

Inductively coupled plasma atomic emission spectrometry (ICP-AES) technique is useful for the determination of a wide variety of elements in geological materials and biological matrices (Pramanik and Das, 2019). It offers higher sensitivity and precision for most elements compared to AAS. In particular, the determination of Gd complexes in rat (Frame and Uzgiris, 1998) and human bone tissues (Gibby et al., 2004), but also in water samples (Liang et al., 2005), soils and sediments (Djingova and Ivanova, 2002) have been reported in literature. Frame and Uzgiris (1998) mentioned a lack in sensitivity of this technique when analysing rat tissues samples, since Gd concentrations must be higher than $400 \mathrm{ng} / \mathrm{mL}$ in order to be detected. Conversely, in Liang et al. (2005) and Djingova and Ivanova (2002) a limit of detection (LOD) between 3 and $57 \mathrm{ng} / \mathrm{L}$ and of $0.4 \mathrm{mg} / \mathrm{kg}$, respectively, has been reported for Gd determination thanks to the addition of preconcentration and separation methods (multiwalled carbon nanotubes - MWNTs and cation exchange separation, respectively) (Djingova and Ivanova, 2002; Liang et al., 2005).

As a spectrometric technique, inductively coupled plasma (ICP) is the most commonly used plasma source mass spectrometry (MS) which had and still has a pivotal role in applied sciences and research applications. Nowadays, ICP-MS is routinely employed in geochemical analyses, as in environmental and life sciences, industrial application (food sector, chemistry, semiconductor, nuclear), forensic sciences and archaeology. An ICP is the standard high-temperature ion source and provides temperatures of approximately $6000 \mathrm{~K}$. In an ICP plasma all the different types bonds are broken independently of their type or strength and therefore, a plasma gives information only about the total amount of an element in the specimen (Ammann, 2007).

Since ICP-MS could only provide information about the total Gd content (Clases et al., 2018), to obtain detailed information on Gd species the application of chromatographic techniques is necessary, to separate each Gd complex in order to analyse them individually. Nevertheless, compounds characterized by hydrophilic properties, like metal ion solutions, weakly interact with the stationary phase of chromatographic columns. In such situations, HILIC has been described as a new robust methodology with enhanced performances and a combination of HILIC-ICP-MS is suitable for Gd speciation analyses and therefore for the quantification of Gd based contrast agents in environmental studies (Raju et al., 2010). However, a high salt content in seawater could cause various problems, among which instrument sensitivity drift and signal suppression. HILIC can be considered as a potent analytical technique to separate polar and hydrophilic compounds, like Gd-based contrast agents, on a polar stationary phase and it is a good alternative for all the compounds that are retained poorly on reversed-phase columns (Raju et al., 2010). Most of the recently published works use conventional nonmodified (naked) silicas as a stationary phase and a polar organic solvent (most commonly used are acetonitrile and less frequently methanol) containing up to 30\% water (see Gama et al., 2012; Hemström and Irgum, 2006 as examples). The elution of a hydrophilic chromatography column with a hydrophobic (mostly organic) mobile phase is particularly useful, since the hydrophilicity of solutes determinates an increase in retention (Alpert, 1990).

A newly developed and useful alternative to avoid matrix effects in seawater REEs determination is the commercially available "seaFAST" system (Elemental Scientific Inc.). This automated system allows to efficiently separate seawater matrix elements (anions and alkali and alkaline earth cations) and elutes the preconcentrated sample directly into the spray chamber of an ICP-MS instrument, not allowing REEs fractionation. Coupling these two techniques appears to guarantee reliable data for the accurate determination of REEs in seawater environments, with a limit of detection (LOD) of $0.017 \mathrm{ng} / \mathrm{L}$ (Hathorne et al., 2012; Fisher and Kara, 2016).

\subsection{Gadolinium chemical speciation}

As reported in Section 1.2.1, clinical studies revealed that magnetic resonance imaging (MRI) Gd complexes are eliminated in nonmetabolised forms by the patients after few hours from the treatment. Moreover, most of the compounds are not removed from wastewater treatment plants (WWTPs) and consequently they can reach freshwater environments (Raju et al., 2010). The reason for this phenomenon might be either explained due to the high solubility of these compounds (they are not sorbed by organic particulate matter) or to their high resistance to microbial degradation (Braun et al., 2017). Understanding which Gd chemical forms occur in the environment will help to distinguish natural from anthropogenic Gd, to achieve a better knowledge of Gd contamination and its anthropogenic and/or natural sources. In particular, it is crucial to assess the stability of the gadolinium-based contrast agents (GBCAs) actually present in seawater environments, with particular reference to extensively used macrocyclic GBCAs (as examples, gadoterate meglumine, gadobutrol and gadoteridol) and also because their worldwide exploitation is growing fast. Studies on this topic would be fundamental to evaluate Gd contamination effects in aquatic systems and to assess reliable water treatment applications (Le Goff et al., 2019). For all these reasons, information on Gd speciation is necessary for environmental and toxicity studies.

Speciation refers to the identification and quantification of the various element forms and species occurring in the different phases (Khan et al., 2016). The physicochemical information collected for each form through speciation analyses may improve the knowledge on their corresponding mobility, pathways, toxicity and bioavailability. Moreover, the analysis and quantification of the various REEs, namely Gd, chemical forms can be performed both in sediments and in water environments (freshwaters and seawaters). REEs chemical speciation add relevant information on possible impacts on the environment due to species bioavailability and their possible origin, above the total contamination (Khan et al., 2016). In order to determine the various pollutant forms', as example occurring in a sediment sample, sequential extractions must be performed. The extraction procedure employed for Gd in sediments is usually the one described by Hall et al. (1996) and depicted in the Fig. 1 of supplementary material. The 5 operational steps correspond to the main fractions (Hall et al., 1996): Fraction I - sorbed/exchangeable/carbonate (AEC); Fraction II - amorphous Fe oxyhydroxide; Fraction III - crystalline Fe oxide; Fraction IV - sulphides and organics; and Fraction $\mathrm{V}$ - residual, mainly silicates. 
The order of mobility of the REEs, including Gd, can be calculated considering their relative abundance in each of the 5 above mentioned fractions. The mobility order is the following: adsorbed/exchangeable/ carbonates (Fraction I) $>$ bound to silicates and residual oxides (Fraction $\mathrm{V}$ ) $>$ bound to sulphides and organics (Fraction IV) $>$ bound to amorphous Fe oxyhydroxides (Fraction II) $>$ bound to crystalline Fe oxyhydroxides (Fraction III) (Khan et al., 2016; Hall et al., 1996). Consequently, the average potential mobility of REEs found by Khan et al. (2016) suggested the following REEs mobility order: $\mathrm{Yb}>\mathbf{G d}>\mathrm{Y}=$ $\mathrm{Dy}>\mathrm{Pr}>\mathrm{Er}>\mathrm{Tm}>\mathrm{Eu}>\mathrm{Nd}>\mathrm{Tb}>\mathrm{Sc}>\mathrm{Lu}>\mathrm{Ce}>\mathrm{La}$. These data are in accordance with Khorasanipour and Rashidi (2020), which stated that HREEs display higher mobility compared to LREEs in the Sarcheshmeh mine (Iran), a highly contaminated site by acid mine drainage. Different conditions can modify and control the mobility of REEs in freshwater and marine ecosystems, including $\mathrm{pH}$ variations, climatic conditions, weathering and rocks composition, dissolution, solubility, ionic radius, dissolved ionic species, alluvial deposits and sorption capacity (Khan et al., 2016). However, it must be mentioned that, giving the low concentration of REEs and the high concentration of the interfering matrix components, quantification of REEs in environmental samples, especially in seawater, is not an easy task. Nevertheless, recent technological advances have led to the development of simpler and easier preconcentration systems, like "seaFAST" (see Section 2.1), which allowed better performances and precision in REEs detection and quantification in seawater. An alternative method for REEs separation is the solid phase extraction (SPE) (Pyrzynska et al., 2016). In this technique, REEs are firstly retained by different water-insoluble solid matrixes and further eluted using acids or complexing reagents. Solid phase extraction procedures provide additional valuable advantages in comparison with classical liquid-liquid extraction, namely reduced organic solvents use and lower risks related to their exposure, high enrichment factor, quick phase separation and the possibility to be combined with other detection techniques (Augusto et al., 2013).

Water samples analysed by Lindner et al. (2013) collected from a German river (Teltow channel, Berlin) in order to determine Gd speciation revealed the presence of two different Gd-containing contrast agents: Dotarem (Gd-DOTA) and Gadovist (Gd-BT-DO3A). These findings were possible thanks to HILIC, combined with inductively coupled plasma mass spectrometry (ICP-MS). The same authors also reported the presence of additional Gd-based contrast agents such as gadobenate dimeglumine (Gd-BOPTA) and gadopentetic acid (Gd-DTPA). These compounds were found in other Berlin (Germany) areas, demonstrating their wide employment in the country. The amount of Gd-DOTA and Gd-BT-DO3A ranged between 456 and $471 \mathrm{ng} / \mathrm{L}$ far above the geogenic background (Lindner et al., 2013). Away from the WWTP outlet, the concentration of both Gd forms decreased approximately 8 times. These data confirmed the absence of any form of degradation of the Gd complexes along the river streams. Altomare et al. (2020) reported Gd concentrations above the geogenic levels (commonly named anomalies) found in the environment in the Orlando Easterly Wetlands (OEW) sediments, detecting an average ratio of anthropogenic over geogenic $\mathrm{Gd}\left(\mathrm{Gd}_{\mathrm{Ant}} / \mathrm{Gd}_{\mathrm{Geo}}\right)$ of 5.34 . Such findings may be related with previous studies conducted by Verplanck et al. (2005) on $\mathrm{Gd}^{3+}$ speciation in water solution, which reported that the metal ions tend to complexate with both carbonate and phosphate anions, if present in high concentrations, once sinking of REEs-phosphate aggregates could be considered as a possible process for Gd inorganic sedimentation (Byrne et al., 1996). Thus, the amount of phosphorus entering the OEW could favour the Gd precipitation through complexation reactions, even if no correlation between phosphorus and Gd has been found (Altomare et al., 2020). Differences in Gd concentration in sediments have been noted according to changes in sediment composition, since samples containing high quantities of sandy material had an inferior amount of anthropogenic Gd (Altomare et al., 2020). On the other hand, samples with greater quantities of total organic carbon, had higher concentrations of anthropogenic Gd. This fact suggested that plants and organic matter in general, could be able to capture Gd through metal uptake or through deposition, respectively (Altomare et al., 2020).

A speciation analysis of sediments in former mining lakes in Malaysia allowed to determine the percentage of Gd metal in each sediment fraction (Khan et al., 2016): 41.8\% of Gd was present in Fraction I (sorbed/exchangeable/carbonate) and 11.0\% in Fraction II (amorphous Fe oxyhydroxide fraction). In the latter fraction, Gd was more abundant than other REEs such as lanthanum (La), yttrium (Y) and cerium (Ce).

Birka et al. (2016a) carried out a specific analysis of water samples from multiple waterworks in a densely populated region near the Ruhr river (Germany). For this purpose, HILIC and ICP-MS have been employed. Analysis of chromatograms showed the presence of different Gd-based contrast agents, namely Gd-DTPA, Gd-DOTA, and Gd-BTD03A in samples collected from various steps of the drinking water purification. Conversely, no noticeable Gd-BOPTA concentrations were determined in any of the samples (Birka et al., 2016a). Therefore, Birka et al. (2016a) results enlightened that different Gd complexes can be identified and quantified in the purified drinking water. Moreover, samples collected from more densely populated regions showed an increasing in the total Gd amount as well as higher concentrations of Gd complexes in the analysed water samples, showing the presence of a significant anthropogenic input. The concentrations of Gd-based contrast agents were also distinctly detectable in the drinking water produced from the related waterworks (Birka et al., 2016a). These results evidenced not only the presence of anthropogenic Gd MRI contrast agents in German rivers, but also that these pollutants are not degraded by conventional purification methodologies, remaining almost unaltered in the drinking water (Birka et al., 2016a).

These data are in accordance with those obtained in another paper published by Birka et al. (2016b) in which solutions of four commonly employed contrast agents have been irradiated with UV light and successively analysed by means of HILIC-ICP-MS. These experiments aimed to test the stability of possible Gd-contrast agents' transformation products, with particular attention on the release of $\mathrm{Gd}^{3+}$ ions resulting from transmetallation reactions. The results showed that the concentration of Gd-BT-DO3A, Gd-DOTA and Gd-DTPA did not decrease after 300 min of irradiation, while a noteworthy decline of the amount of Gd-BOPTA have been reported. This latter fact can be explained considering that Gd-BOPTA possesses an aromatic ring, which is known to be less stable towards UV radiation. A further experiment investigated the photochemical degradation of Gd-BOPTA with a maximum irradiation time of $300 \mathrm{~min}$ in various environmental conditions of the water purification steps (Birka et al., 2016b). The result obtained showed a significant decrease of the Gd-BOPTA signal, with the consequent formation of different sub-products whose concentration increased with the rise of the irradiation time. Due to the employment of HILIC coupled with ICP-MS, it was possible to evaluate that the degradation of GdBOPTA varied according to the matrix considered. Moreover, HILIC coupled with electrospray ionization mass spectrometry (HILIC-ESIMS) measurements were carried out in order to ultimately obtain information on the chemical structure of the degradation products (Birka et al., 2016b).

\subsection{Gadolinium concentrations in aquatic environments}

Twelve years after its first employment, in 1996, anthropogenic Gd was observed in German rivers (Bau and Dulski, 1996). Many researchers reported similar discoveries in different countries such as France, USA, China, Brazil and Turkey (Alkan et al., 2020; Altomare et al., 2020; Barber et al., 2015; Hatje et al., 2016; Parant et al., 2018; Perrat et al., 2017; Pedreira et al., 2018; Pereto et al., 2020; Rabiet et al., 2009; Zhao et al., 2007; Zhou et al., 2012) but also in Kazakhstan, Portugal, Republic of Benin and Australia (Pratas et al., 2017; Rzymski et al., 2019; Xu et al., 2018; Yessoufou et al., 2017) in much lower concentrations. Nevertheless, in this review, only 
noteworthy reported Gd anomalies will be discussed (Table 1supplementary material).

The presence of anthropogenic Gd has been detected in surface and drinking water (Birka et al., 2016a), indicating that WWTPs are not able to fully and effectively remove contrast agents' complexes. A study regarding this issue demonstrated that only about $10 \%$ of Gd is eliminated during these depuration processes while only advanced waste water treatment plants (WWTPs) are able to remove 100\% of it (Rogowska et al., 2018). Gd persistence in complexated forms in environmental matrices suggest that anthropogenic Gd could be used as a tracer element for the detection of REEs dissolved in rivers, but also to detect their final input into seawater and many other monitoring activities (Kulaksız and Bau, 2007). In fact, analysis performed in German river basins, reported the presence of a considerable amount of anthropogenic Gd which is thought to be the main reason for the positive $\mathrm{Gd}$ anomalies reported in coastal seawater. This scenario has been noticed in the southwestern North Sea and off the coast of the East Frisian Islands, where anthropogenic Gd is thought to be majorly derived from the rivers Rhine and Thames (Kulaksiz and Bau, 2007). A further proof that the positive Gd anomalies have anthropogenic origin comes from the fact that rivers in scarcely populated and non-industrialized areas in central Sweden and Japan do not show important concentration of Gd compared to the majority of German rivers (Rhein, Elbe, Mosel Wupper, Spree and Havel) (Bau and Dulski, 1996).

Evidences coming from the analysis of Gd-contaminated water samples showed that these anomalies are probably due to the employment of gadopentetic acid ( $\left.\mathrm{Gd}(\mathrm{DTPA})^{2-}\right)$ in magnetic resonance imaging (MRI), particularly employed from the 1980s. It is worthy to mention that not only rivers, but also semi-closed sea basins, lakes and coastal seas can be considered as final containers for REEs inputs coming from industrialized and populous areas, contributing to the spreading of the contaminant along worldwide waters (Bau and Dulski, 1996).

\subsubsection{Freshwater environments}

Recent literature reported the presence of Gd freshwater anomalies in different countries worldwide (Table 1-supplementary material). During 1990s in German hospital's effluents, Gd emission ranged between 2.1 and $4.2 \mathrm{~kg} /$ year, generating a predicted concentration of 8.5-30.1 $\mu \mathrm{g} / \mathrm{L}$ (Kummerer and Helmers, 2000), while in 2013 approximately $12 \mathrm{t}$ of Gd per year, used for biomedical purposes, were released through sewages into the environment (Cyris, 2013). Moreover, relying on data concerning Gd utilization, the total release of this metal by German hospitals was calculated to be approximately $132 \mathrm{~kg}$ per year in 1994. An increment of the normally occurring concentrations of Gd in German surface waters by $0.003-0.004 \mu \mathrm{g} / \mathrm{L}$ is thought to result if there will be no eradication of this metal through wastewater treatment plants (Kummerer and Helmers, 2000). Considering the total number of MRI machineries employed in Germany by hospitals and practices, the annual emission has been stated between 484 and $1160 \mathrm{~kg}$ which will lead to a further Gd concentration in German surface water ranging between 0.011 and $0.026 \mu \mathrm{g} / \mathrm{L}$, respectively (Kummerer and Helmers, 2000). Hence, on the basis of the data collected, the release of Gdbased contrast agents used in MRI must be treated as one of the main sources of anthropogenic Gd anomaly in German surface waters (Kummerer and Helmers, 2000). Considering that all major rivers in north western Germany flow into the North Sea, bringing with them positive Gd anomalies, high Gd levels should be found in this coastal area. As normally happens, a significant percentage of the commonly occurring REEs in rivers is made by colloids, which carry up to $90 \%$ of the total dissolved REEs (particularly in those rivers containing high concentrations of dissolved organic carbon - DOC). These colloids aggregate during mixing between freshwater coming from river effluents and seawater of estuaries (Kulaksız and Bau, 2007). As a consequence, a fraction of the solubilized REEs is withdrawn from the river water, entrapped in the colloids. Conversely, anthropogenic Gd species have an opposite behaviour. In fact, they remain unaltered during the estuarine water mixing, barely changing their chemical proprieties and composition. This highlights a marked difference in the speciation of anthropogenic Gd from the geogenic one. Due to its strong stability, a longer environmental half-life of the anthropogenic Gd complexes is expected (Kulaksız and Bau, 2007).

Barber et al. (2015), instead, evaluated the occurrence of many pollutants released from WWTPs into streams in the Great Lakes and Upper Mississippi River Regions (USA), through a 10-years-long monitoring (from 1999 to 2009). Among all the contaminants reported, Gd was present in noteworthy concentrations in the Calumet WWTP effluent, situated in the highly industrialized area between the city of Chicago, Illinois and Gary, Indiana (Barber et al., 2015). These findings further demonstrate the lack of removal of Gd through any of the WWTPs treatments employed and illustrate the potential persistence of this contaminant, which can easily be linked to specific human activities, such as medical facilities performing MRI analysis (Barber et al., 2015). Also in USA, Altomare et al. (2020) highlighted the presence of noteworthy anthropogenic Gd concentrations in the Orlando Easterly Wetlands (Florida) which is one of the biggest wetland treatment systems in the state. The presence of several hospitals and smaller medical facilities in this area constitute an anthropogenic source of $\mathrm{Gd}$, which has been detected both in the wetland water (values ranging between 422 and $555 \mathrm{ng} / \mathrm{L})$ and in sediments $\left(\mathrm{Gd}_{\mathrm{Ant}} / \mathrm{Gd}_{\mathrm{Geo}}\right.$ ratio on average of 5.34). According to the data collected, the overall Gd input in this area is thought to be of approximately $25 \mathrm{~g}$ of Gd/day (Altomare et al., 2020).

Noteworthy positive Gd anomalies were routinely observed in WWTP effluents in southern and western France (Rabiet et al., 2009; Pereto et al., 2020). These findings demonstrated that Gd can be also found in wastewater coming from rural communities, in which MRI facilities are not present. Gadolinium concentrations beyond the geogenic background were found in two affluents of the Hérault River and in some wells providing drinking water, with a positive anthropogenic Gd anomaly in water up to $2.4 \mathrm{ng} / \mathrm{L}$ (Rabiet et al., 2009). A monthly monitoring on one well has confirmed the persistence of Gd anomalies all along the year, suggesting a continuous wastewater contamination on the site (Rabiet et al., 2009). In addition, anthropogenic Gd was found in the Mosel river, close to the WWTPs of the cities of Metz and Nancy, and in the Jalle River, near the city of Bordeaux. Analysis showed that the total amount of metal in the water samples varied between 40 and $630 \mathrm{ng} / \mathrm{L}$, with an estimation of the anthropogenic Gd reaching $67 \%$ of the total Gd in the former case, and between 58.0 and $132.5 \mathrm{ng} / \mathrm{L}$ with an estimation of the anthropogenic Gd between 2.8 and $86.9 \mathrm{ng} / \mathrm{L}$ in Bordeaux (Perrat et al., 2017; Pereto et al., 2020). Further studies detected anthropogenic Gd anomalies in the Lorraine region rivers, with noteworthy REE concentrations reaching peaks of more than $80 \mu \mathrm{g} / \mathrm{L}$ near the WWTPs (Parant et al., 2018). These amounts undergo further dilution along the river stream and were measured to be around 10 $\mathrm{ng} / \mathrm{L}$ near areas from which drinking water is collected (Parant et al., 2018). The high variability in the data collected, could be related to the population density. In fact, Gd anomalies are condensed in the biggest cities where most of the MRI analysis is performed. These data also showed that the use of gadolinium-based contrast agents (GBCAs) is constantly increasing, leading to a growing associated waste released into river waters (Parant et al., 2018).

Zhao et al. (2007) reported the presence of REEs in an acid mine drainage in the Shanxi Province, North of China. On their study, positive REEs anomalies were found compared to the geogenic background. The whole amount of these elements ranged from 54.37 to $68.80 \mu \mathrm{g} / \mathrm{L}$ while Gd concentration ranged between 3.18 and $4.27 \mu \mathrm{g} / \mathrm{L}$. Among all the rivers considered, Shili River was found to be enriched with Sm, Eu, and Gd while other effluents located near mining areas showed REEs values three orders of magnitude higher than those of other river waters in Northern China (Zhao et al., 2007). In addition, in the Yellow river in Baotou, REEs concentrations both in water and sediments samples were reported to be 200 times higher compared to other rivers in Northern China (Zhou et al., 2012), while in the Maluan Bay, anomalies 
involving both LREE and HREE elements have been reported in all the water samples collected (Wang et al., 2019). In the Sidaosha River samples had an overall concentration of REEs of $31.52 \mu \mathrm{g} / \mathrm{L}$ in suspended particles and $30.46 \mu \mathrm{g} / \mathrm{L}$ in sediments (Zhou et al., 2012). The concentration of $\mathrm{Gd}$ in river water samples $(4.55 \mathrm{mg} / \mathrm{L})$ was lower compared to other REEs, also determining a high variability of the collected data (Zhou et al., 2012).

One of the highest Gd anomalies published in literature have been reported in Turkish rivers. In fact, according to the Organization for Economic Co-operation and Development (OECD), Turkey occupies the first place considering the number of equipment and applications of MRI imaging in the world (OECD, 2015). Despite this fact, there is no research on the possible effects of this metal on the environment across the country. In the study performed by Alkan et al. (2020), Gd concentrations have been measured in water and sediment samples collected from various locations in the Ankara Stream (Turkey) and its tributaries. The highest mean Gd concentration was found to be 0.347 $\pm 0.057 \mu \mathrm{g} / \mathrm{L}$ in water samples, which was one of the highest values among most rivers in the world (Alkan et al., 2020). For what concerns the Gd concentration in sediment samples, Alkan et al. (2020) found an average value of $3.52 \mathrm{mg} / \mathrm{kg}$, with no statistically relevant difference among all the sampling sites. Gd concentrations measured in sediments demonstrated to have high correlation with other lanthanides (such as: $\mathrm{Nd}, \mathrm{Sm}, \mathrm{Eu}, \mathrm{Pr}, \mathrm{La}, \mathrm{Tb}, \mathrm{Ho}, \mathrm{Dy}, \mathrm{Er}, \mathrm{Tm}$ ). This can suggest that Gd is likely of geological source (Alkan et al., 2020). On the contrary, lower correlation between Gd and other lanthanides in water samples reinforced the possibility that Gd behaves differently from other REEs in aquatic environments and thus can be considered to be of anthropogenic origin (Alkan et al., 2020).

\subsubsection{Marine environments}

Published literature reported that Gd concentrations above the geogenic background can be detected also in marine and coastal waters (Table 1-supplementary material). In fact, analyses performed in San Francisco Bay (SFB, USA) showed a constant increase in the Gd concentration over time, starting from the first years of 1990 to nowadays (Bau and Dulski, 1996; Hatje et al., 2016). The most considerable Gd anomalies were noticed in the southern area of SFB, where many medical facilities and research centres which employ Gd-based contrast agents (GBCAs) for MRI occur. The current increase of these Gd compounds usage most likely played a major role in the rising of anthropogenic Gd amounts in SFB, which passed from 1.3 to $17.6 \mathrm{ng} / \mathrm{L}$ (8.27 to 112 $\mathrm{pmol} / \mathrm{kg}$ ) during the past 20 years (Hatje et al., 2016). These data are in accordance with other researches which stated that anthropogenic Gd complexes seemed to act in a conservative way throughout the fresh and seawater mixing, persisting into the environment (Kulaksız and Bau, 2013).

Water samples have been also analysed from the coast of Northeastern Brazil, near the city of Salvador, in order to examine the impact of two submerged sewage outfalls on Gd distribution along the coast (Pedreira et al., 2018). The concentrations of Gd above the geogenic background have been detected in most of the considered sampling zones. This could be an insight on the occurrence of anthropogenic Gd also in coastal waters. The most remarkable Gd anomalies have been detected in the proximity of the submarine sewage outfalls with a decreasing concentration as the distance increases from the point source (Pedreira et al., 2018). The total Gd discharge per day has been calculated to be around $216 \pm 82 \mathrm{~g}$ for the Rio Vermelho zone and $92.0 \pm$ $19 \mathrm{~g}$ for Boca do Rio submarine outfalls, respectively. According to the estimation reported by De Campos and Enzweiler, in 2016, the amount of anthropogenic $\mathrm{Gd}$ released by hospitals and clinics in Brazil varied between $527 \mathrm{~kg}$ and $5.3 \mathrm{t}$ (De Campos and Enzweiler, 2016). In particular, it was roughly calculated that a quantity between 698 and $2021 \mathrm{~g} \mathrm{Gd}$ per day has been discharged into the Tropical and South Atlantic oceans due to submarine outfall sewage along the Brazilian coasts (Pedreira et al., 2018).
Overall, the whole information above mentioned regarding Gd concentrations in aquatic environments, reveal that Gd anomalies could be detected both in marine and freshwater systems, highlighting a high diffusion of this metal. The highest Gd values were found in freshwater samples, especially in France (particularly the Lorraine region), Germany and Turkey, with concentrations reaching 80, 30.1, and $0.347 \mu \mathrm{g} / \mathrm{L}$, respectively.

\subsection{Gadolinium bioaccumulation in aquatic organisms}

Published literature concerning REEs showed that aquatic organisms are able to uptake REEs from waters (Cyris, 2013; Rogowska et al., 2018; Freitas et al., 2020a, 2020b; Mestre et al., 2019; Pinto et al., 2019) and from sediments (Pastorino et al., 2020). Like other chemical elements, Gd toxicity is influenced by the characteristics of the organisms exposed such as age, size, the type of exposure (chronic - for a long period of time; or acute - for a short period of time) and the concentrations of other REEs in solution. Researches have shown that dose-response relationship of these metals are generally biphasic, with stimulatory or beneficial effects at low exposure concentrations, and inhibitory or toxic effects at high concentrations (Pagano et al., 2015). Several studies have shown that low REE quantities are able to favour the growth of both terrestrial and aquatic animals, some of which have been used since 1990 as micronutrients in fertilizers and more recently as livestock feed additives (He and Rambeck, 2000; Xun et al., 2014). Gadolinium and in general all REEs toxicity studies have focused particularly on species of economic interest or those related directly to public health, such as the bacteria Vibrio fischeri (González et al., 2015), the algae Raphidocelis subcapitata and those belonging to Chlorella species (Hao et al., 1997; Fujiwara et al., 2008; Balusamy et al., 2015; González et al., 2015; Joonas et al., 2017). Nevertheless, researches involving more marine and freshwater species have been reported recently, thus covering a greater biodiversity (Blaise et al., 2018; Pinto et al., 2019; Duarte and Caçador, 2020; Freitas et al., 2020a, 2020b; Henriques et al., 2019; Moreira et al., 2020).

\subsubsection{Environmental exposure to gadolinium}

Concentrations of Gd in different freshwater and marine invertebrate species under in situ conditions are reported in Table 2-supplementary material.

2.4.1.1. Bioaccumulation in freshwater invertebrates. In the study performed by Perrat et al. (2017), the effects of Gd in two freshwater bivalve species, namely Dreissena rostriformis bugensis and Corbicula fluminea were evaluated through an in-situ experiment (exposition in the environment). For this purpose, Gd concentration has been determined in organisms' tissues after exposing them for 7 and 21 days in 4 different locations in the Mosel River, France, close to a wastewater treatment plant (WWTP) of Metz city. Water samples revealed the presence of anthropogenic $\mathrm{Gd}$, with concentration estimated to vary from 40 to $630 \mathrm{ng} / \mathrm{L}$ (Perrat et al., 2017). The results of Gd bioaccumulation in bivalves were also assessed, using specimens collected from different sampling areas, placed before and after the WWTP. In the whole organism, for both $D$. rostriformis bugensis and $C$. fluminea, any remarkable differences were noticed between the two sampling sites after 21 days of exposure. These results suggested that the WWTP did not alter in any way the bioaccumulation of Gd in the organism tested in these experimental conditions, further evidencing that these filtering systems are not able to retain these emerging contaminants, which are instead released unchanged into the environment (Raju et al., 2010; Perrat et al., 2017).

These bioaccumulation studies conducted by Perrat et al. (2017) have been performed focusing at first on the animals' gills. The bioaccumulation values were almost zero after 7 and 21 days of exposure for C. fluminea while an increase in Gd accumulation over time was noticed for $D$. rostriformis bugensis. The same procedure has been performed for 
the digestive gland as well. In this case time dependence was only partly detected. In addition, Gd concentrations in D. rostriformis bugensis were superior compared to $C$. fluminea after an exposure period of 21 days. A possible explanation of the conflicting results obtained, could be the enhanced activity of the defence mechanisms by $C$. fluminea, particularly in the gills (Perrat et al., 2017). According to what was reported by Achard et al. (2004), it is possible to assume that a multixenobiotic resistance is principally responsible for the enhanced defence mechanism present in C. fluminea (Achard et al., 2004). This type of protection system could be able to expel both Gd ions and other Gd species out of the gills, through complexation with different organic compounds or particles. Data concerning bioaccumulation of Gd for both species showed that Gd accumulation in bivalve tissues occurs either when organisms are exposed to a solution containing both geogenic and anthropogenic Gd (in-situ experiment, Table 1) and to a single Gd complex (GdDOTA, Table 1) (Perrat et al., 2017). Even if the in-situ Gd water concentrations were much lower (40-630 ng/L) compared to the one present in the laboratory experiment $(1,10 \mu \mathrm{g} / \mathrm{L})$, an overall higher bioaccumulation of this pollutant in the former case has been reported. This result could majorly be due to the different Gd speciation. In fact, as enhanced in other papers (Hanana et al., 2017; Le Goff et al., 2019), chelated gadolinium-based contrast agents (GBCAs) are less bioavailable compared to free Gd ions. In addition, it must be pointed out that, due to the technical approach used in the above mentioned study (determination of Gd concentrations by ICP-MS analysis) it has not been possible to distinguish the anthropogenic Gd from the geogenic one present in bivalves' tissues during the in-situ experiment.

In accordance with these results, in-situ studies performed by Pereto et al. (2020) reported Gd bioaccumulation in C. fluminea soft tissues in the Jelle River (Bordeaux area, France), near a WWTP effluent, with a total Gd concentration ranging from $49 \pm 4$ to $110 \pm 19 \mathrm{ng} / \mathrm{g}$ d.w. (dry weight). Anthropogenic Gd concentration instead has been estimated to range between $1.5 \pm 1.0$ and $4.1 \pm 0.7 \mathrm{ng} / \mathrm{g}$ d.w. Despite the lower bioavailability and concentration in river waters of $\mathrm{Gd}_{\text {anth }}$ compared to $\mathrm{Gd}_{\text {geo }}$, a clear bioaccumulation of this contaminant in C. fluminea has been observed. For this reason, this species could be used as a suitable model species to track REEs contaminations, including GBCAs (Pereto et al., 2020).

Le Goff et al. (2019) pointed out that Gd can be also accumulated in bivalves' shells, being the analysis of the shell composition useful to determine the presence of anthropogenic REEs in water environments (Le Goff et al., 2019). On this topic, Merschel and Bau (2015) reported an unusual Gd accumulation in C. fluminea shells collected in the Rhine river, Germany. The concentrations values of REEs in $C$. fluminea shells were highly variable. These results suggested that metal accessibility in the environment was not the only responsible for the data diversity. In fact, Weltje et al. (2002) reported that Gd bioaccumulation in the soft tissue of seven mollusc species, including the bivalves $C$. fluminea and $D$. polymorpha, varied greatly between the various species and sampling sites. This could be due to differences in feeding and burrowing behaviour, but also due to $\mathrm{pH}$ of the (pore) water. Therefore, a similar behaviour can be hypothesized for Gd complexes (mainly Gd-DOTA), as they are known to be particularly sensitive to pH (Kálmán et al., 2007; Wang et al., 1992), temperature, concentration (Sherry et al., 2009a, b),
Table 2

Rare earth elements (REEs) concentrations in freshwater samples (ng/kg) from the Rhine and Weser Rivers and in Corbicula fluminea shells ( $\mu \mathrm{g} / \mathrm{kg} \mathrm{d.w.)} \mathrm{for} \mathrm{different} \mathrm{locations} \mathrm{at} \mathrm{the}$ Rhine and Weser Rivers.

Data have been adapted from Kulaksız and Bau $(2007,2013)$ and Merschel and Bau (2015).

\begin{tabular}{cccccc}
\hline & \multicolumn{2}{l}{ REEs in water samples $(\mathrm{ng} / \mathrm{kg})$} & & \multicolumn{2}{l}{ REEs in C. fluminea shells $(\mu \mathrm{g} / \mathrm{kg})$} \\
\cline { 2 - 3 } \cline { 5 - 6 } \cline { 5 - 6 } & Rhine River & Weser River & & Rhine River & Weser River \\
\hline La & $31.88^{\mathrm{a}}$ & 10.50 & & $493.16^{\mathrm{a}}$ & 64.70 \\
$\mathrm{Sm}$ & $3.90^{\mathrm{a}}$ & 3.26 & & $8.55^{\mathrm{a}}$ & 12.10 \\
$\mathrm{Gd}$ & $11.54^{\mathrm{a}}$ & 19.40 & & $6.82^{\mathrm{a}}$ & 11.60 \\
\hline
\end{tabular}

a Data averaged from REEs concentrations measured in different locations of the Rhine river, Germany.

salinity and the presence of negative counter ions (Sneller et al., 2000). REEs concentrations in organisms' shells have been reported by Kulaksız and Bau $(2007,2013)$ and Kulaksız and Bau (2011) (Table 2). From the analysis performed, it was demonstrated that the detection of anthropogenic positive Gd anomalies in Rhine River and Weser River waters was not found in C. fluminea shells. While anthropogenic La and Sm originating from industries close to the Rhine River waters were immediately uptaken and integrated into the shell, the anthropogenic Gd coming from medical facilities and discharged through WWTPs into the German rivers acted in an opposite manner. Therefore, the former scenario highlights the enhanced bioavailability of these REEs. Moreover, since their presence has been also spotted in drinking water along the Rhine River, further studies on their possible toxic effects are required. The incorporation of anthropogenic Gd in these organisms' shells further evidences the long environmental half-life of the Gd-complexes employed in the medical field (Laurent et al., 2006). These data contribute also to highlight once again that the conservative behaviour of anthropogenic Gd makes it a useful indicator of WWTP effluents in river, lake, ground and tap waters (Merschel and Bau, 2015).

2.4.1.2. Bioaccumulation in marine invertebrates. Le Goff et al. (2019) studied REEs accumulation in great scallop (Pecten maximus) and a comparison among shell samples collected from different bivalve species in different worldwide coastal areas was performed. On this topic, pronounced Gd anomalies in mollusc shells' chemical composition have been noted in coastal areas all around the word, representing an increasing threat for marine organisms. Moreover, these authors highlighted that the REEs trends in scallops were comparable to those of other coastal shellish, suggesting that Gd could be uptaken by a wide variety of molluscs, regardless of their species.

It must be mentioned that in bivalves, shell composition comes from organic molecules, inorganic particles and water which is then uptaken by the molluscs. For this reason, through the analysis of the organisms' shell composition it is possible to evaluate the concentrations of each element in the aquatic environment at the time of shell formation (Markich et al., 2002). In this regards, P. maximus revealed significant positive Gd anomalies, which means that shells assimilated small amounts of anthropogenic $\mathrm{Gd}(\Delta \mathrm{Gd}=0-2.3 \mathrm{ng} / \mathrm{g})$, which displayed an intricate evolution over time. Samples collected in 1960, before the

Table 1

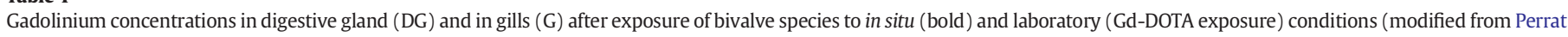
et al., 2017). Concentrations are expressed in ng/g (d.w.).

\begin{tabular}{|c|c|c|c|c|c|c|c|c|}
\hline & \multicolumn{4}{|c|}{ Dreissena rostriformis burgensis } & \multicolumn{4}{|c|}{ Corbicula fluminea } \\
\hline & \multicolumn{2}{|l|}{ DG } & \multicolumn{2}{|l|}{ G } & \multicolumn{2}{|l|}{ DG } & \multicolumn{2}{|l|}{ G } \\
\hline & 7 days & 21 days & 7 days & 21 days & 7 days & 21 days & 7 days & 21 days \\
\hline In situ & $75 \pm 15$ & $100 \pm 18$ & $11 \pm 9$ & $123 \pm 34$ & $\mathbf{6} \pm \mathbf{0}$ & $57 \pm 24$ & $\mathbf{0} \pm \mathbf{0}$ & $8 \pm 7$ \\
\hline $1 \mu \mathrm{g} / \mathrm{L}$ & $6.0 \pm 5.8$ & $77.8 \pm 11.8$ & $0.0 \pm 0.0$ & $4.7 \pm 6.2$ & $6.4 \pm 6.2$ & $33.4 \pm 2.6$ & $0.0 \pm 0.0$ & $5.4 \pm 4.0$ \\
\hline $10 \mu \mathrm{g} / \mathrm{L}$ & $25.0 \pm 4.8$ & $203 \pm 27.8$ & $0.0 \pm 0.0$ & $28.8 \pm 8$ & $5.4 \pm 6.0$ & $100.4 \pm 19$ & $0.0 \pm 0.0$ & $57.4 \pm 3.0$ \\
\hline
\end{tabular}


use of GBCAs, did not display the presence of Gd anomalies. Instead, a noteworthy rise in Gd excesses has been observed from 1989 to 2005, but a sudden decrease has been reported afterwards, until 2010 when normal levels have been observed again (Le Goff et al., 2019). The anomaly in organisms' shells seem to have risen again, although without reaching the 2005 maximum level. This unexpected trend is in marked contrast with the GBCAs usage during the years. The employment of GBCAs has increased from the first time they were introduced on the market. GBCAs were considered as safe compounds from 1988 to 2006, to such an extent that during the period between 2004 and 2005, these compounds were considered as suitable replacement for iodine-based contrast agents in patients with renal failure for CT (computed tomography) and in interventional studies (Ramalho et al., 2016). This trend could be explained considering the bioavailability of anthropogenic Gd through the determination of its speciation in marine environments. From the early 90s to the present days, a wide variety of GBCAs has been employed and their reactivity in seawater could differ strongly among each Gd chemical species. Le Goff et al. (2019) focused their analysis on those GBCAs which were majorly used prior to 2007 in France: gadoterate meglumine (Gd-DOTA - Dotarem), gadopentetate dimeglumine and gadodiamide (Gd-DTPA - Magnevist and Gd-DTPABMA - Omniscan respectively). In 2005, convincing proofs of a possible correlation between nephrogenic systemic fibrosis and the inoculation of linear GBCAs in patients' body were pointed out (Le Goff et al., 2019; Grobner, 2005; Marckmann, 2006). Due to this fact, the administration of some of these compounds were drastically lowered, in particular the gadopentetate dimeglumine (Grobner, 2005; Marckmann, 2006). As a consequence, a quick decrease of the Gd excesses in bivalves' shells has been reported, which is coherent with the ceasing in the production of this complex. Today, Gd utilization by medical facilities in France is three times higher than the amount reported in 2005 data. Nevertheless, this escalation is not recorded by organisms' shells. This fact can be considered as a further proof towards the hypothesis of a scarce bioavailability of anthropogenic Gd found in seawater environments (Le Goff et al., 2019).

From the whole information regarding Gd concentrations in freshwater and marine invertebrates, it is possible to conclude that one of the main reasons of GBCAs low bioavailability can be attributed to their high stability in freshwater. In fact, previously described, anthropogenic Gd does not appear as a very reactive species, and therefore it can be employed as a useful marker of WWTPs systems (Kulaksız and Bau, 2007). Even if accumulation of Gd has been identified in digestive glands and gills of some freshwater bivalves (Perrat et al., 2017) any significant Gd anomalies have been found in their shells. Very scarce information is available about the stability of GBCAs in marine waters, with only few studies regarding Gd-DTPA. Schijf and Christy (2018) reported that this complex immediately dissociates after the mixing of freshwater coming from river streams with seawater in estuaries. After this degradation process occurs, the Gd ion can be released, thus increasing its bioavailability and toxicity. This behaviour could explain the incorporation of anthropogenic Gd bivalves' shells reported between the years 2005-2006. The absence of a definite connection between the Gd anomalies in the organisms' shells and the usage of Gd contrast agents from 2010 to the present days could indicate the extreme stability of these compounds in seawater environments. Despite linear GBCAs are less employed nowadays in France (only 10\% of Gd used in MRI was in the form of linear GBCAs in 2017), Gd anomalies are however recorded in shellfish.

\subsubsection{Laboratory exposure to gadolinium}

Concentrations of $\mathrm{Gd}$ in different freshwater and marine invertebrate species under laboratory exposure conditions are reported in Table 2-supplementary material.

2.4.2.1. Bioaccumulation in freshwater invertebrates. Perrat et al. (2017) studied the impacts of Gd in two freshwater bivalve species, namely
D. rostriformis bugensis and C. fluminea. Organisms' Gd uptake was analysed using specific exposure concentrations $(0,1$ and $10 \mu \mathrm{g} / \mathrm{L})$ and the bioaccumulation was determined in bivalves' tissues after an exposure period of 7 and 21 days (Table 1 ). In the experiment, Gd was only used in the form of the Gd-contrast agent (Gd-CA) gadoteric acid (GdDOTA - Dotarem ${ }^{\circledR}$ ). Due to the high stability and to the absence of any transmetallation reactions involving gadoteric acid (Laurent et al., 2006), no other origin of Gd was probable during the experimental period. After exposing organisms to $1 \mu \mathrm{g}$ of Dotarem ${ }^{\circledR}$, any significant $\mathrm{Gd}$ concentrations were detected in the gills for both $D$. rostriformis bugensis and C. fluminea after 7 days. Small traces of Gd were instead measured after 21 days. An increasing bioaccumulation over time was noticed in the digestive gland of both organisms with higher Gd values when compared to the gills tissue. These data could be explained by the fact that the defence mechanisms present in the gills were more effective in Gd detoxification. This fact is expected since gills are the first tissues interacting with the external medium due to the filtering activity (Perrat et al., 2017). Upon the organisms' exposure to $10 \mu \mathrm{g} / \mathrm{L}$ of GdDOTA, a time-dependent uptake was noted for both bivalve species, namely $D$. rostriformis bugensis and $C$. fluminea. Consistently to the previous experiment, enhanced Gd concentrations were measured in the digestive gland with respect to those noticed in the gills. However, a difference between the two species was noticed, since Gd concentrations in the digestive gland of $D$. rostriformis bugensis were superior to those found in C. fluminea, indicating a higher efficacy of the defence mechanisms in this species's tissue. Concentrations of Gd accumulated by both species are reported in Table 1, where a slight bioaccumulation of Gd-DOTA can be noticed. This can be easily attributed to the fact that chelated GBCAs, such as Gd-DOTA employed in this experiment, are less bioavailable compared to free Gd ions. However, even if in lower extent, bioaccumulation of Gd coming from gadoteric acid (Dotarem ${ }^{\circledR}$ ) has been observed. For this reason, further research must be performed to determine more accurately the bioaccumulation mechanisms of these contrast agents in various aquatic organisms.

Hanana et al. (2017) tested the capacity of $D$. polymorpha to bioaccumulate $\mathrm{Gd}$ in two speciation forms: $\mathrm{GdCl}_{3}$ and the $\mathrm{Gd}$-contrast agent Omniscan. In this experiment, mussels have been collected in Saint-Laurence river, Quebéc, Canada and successively exposed to raising concentrations of $\mathrm{GdCl}_{3}$ and Omnsican (10, 50, 250 and $\left.1250 \mu \mathrm{g} / \mathrm{L}\right)$ for 28 days. Analysis performed in the soft tissue of mussel exposed to $\mathrm{GdCl}_{3}$, indicated a significant dose dependent increase in Gd concentration, with values reaching $44.97 \mathrm{mg} / \mathrm{kg}$ w.w. (wet weight) at the highest exposure concentration. Conversely to what exhibited by $\mathrm{GdCl}_{3}$, exposure to Omniscan showed a lower amount of Gd detected in organisms' soft tissues for all exposure concentrations (reaching $0.3 \mathrm{mg} / \mathrm{kg}$ w.w. at the highest exposure concentration). These findings could suggest that Omniscan does not significantly dissociate, thus avoiding the liberation of the toxic $\mathrm{Gd}^{3+}$ ion (Hanana et al., 2017). This is probably caused by the strong interactions between $\mathrm{Gd}$ ions and the diethylenetriaminepentaacetate ligand. A further proof of this behaviour was formerly mentioned in other papers in literature, showing that the low conductivity of Omniscan solution was due to the low amount of free Gd in solution (Normann et al., 1995).

2.4.2.2. Bioaccumulation in marine invertebrates. Henriques et al. (2019) determined Gd concentration in Mytilus galloprovincialis' soft tissues after a chronic exposure period of 28 days. From these data it can be noted that in mussels exposed to the lowest pollutant concentration $\left(15 \mu \mathrm{g} / \mathrm{L} ; \mathrm{Gd}_{2} \mathrm{O}_{3}-\right.$ Alfa Aesar Specpure ${ }^{\circledR}$ plasma standard solution $)$ as well as in the control ones, Gd quantities were below the quantification limit of the inductively coupled plasma mass spectroscopy (ICP-MS) used ( $\mathrm{LOQ}=0.38 \mu \mathrm{g} / \mathrm{g}$ ). Analysis performed in mussels exposed to higher concentrations (30,60 and $120 \mu \mathrm{g} / \mathrm{L}$ ) revealed the presence of the element, with contents ranging from $0.44 \pm 0.10 \mu \mathrm{g} / \mathrm{g}$ d.w. to 2.5 $\pm 0.50 \mu \mathrm{g} / \mathrm{g}$ d.w.. The bioconcentration factors (BCFs), defined as the ratio between Gd concentration in mussels' tissue at the end of the 
exposure and Gd initial concentration in water, were shown to be independent from the exposure conditions. These results evidence the capacity of mussels to accumulate Gd, with a direct relationship between accumulation and exposure concentration (Henriques et al., 2019).

\section{Effects of gadolinium in aquatic invertebrate species}

Pollutants discharged in water environments usually changes cellular balance between prooxidant mechanisms and antioxidant defences of the target cell. In particular, studies employing marine (Freitas et al., 2020a, 2020b; Henriques et al., 2019; Pinto et al., 2019; Mestre et al., 2019) and freshwater (Hanana et al., 2017; Perrat et al., 2017; Blinova et al., 2018) species, demonstrated that they are negatively affected by REEs, which often cause alterations on the oxidative status of the animals. These chemicals can both reduce the antioxidants capacity to eliminate oxyradicals or enhance the intracellular formation of the so-called reactive oxygen species (ROS). Reactive oxygen species are generated during different cellular pathways of aerobic metabolism and may cause damage to lipids, proteins and DNA (Regoli and Giuliani, 2014). Normally, the adverse effects of oxyradicals are prevented by the antioxidant system, including low molecular weight scavengers and antioxidant enzymes (Regoli and Giuliani, 2014). Scavengers neutralize ROS by direct reaction with them, acting as antioxidants in the cytoplasm or are intended to arrest the propagation of lipid peroxidation reactions on the membranes. The most abundant cytosolic scavenger is the reduced glutathione (GSH), which directly neutralizes several reactive species through its oxidation to glutathione disulfide (GSSG) (Regoli and Giuliani, 2014). Under a stressful condition GSSG content is enhanced above the reducing capacity of glutathione reductase (GRed) and the ratio GSH/GSSG is altered, decreasing along the increasing stress level. The ratio GSH/GSSG has been frequently used as an indicator of cellular redox status after exposure to pollutants (Freitas et al., 2020a). Compared to scavengers, which interact with more than one type of ROS, enzymatic antioxidants (such as, superoxide dismutase, catalase and glutathione peroxidase) catalyse highly specific reactions with particular substrates.

In addition to the determination of oxidative stress biomarkers, having insights about the metabolic activity of the organism under study, especially after its exposure to pollutants, it is of paramount importance. Energy consumption is estimated by measuring the electron transport activity (ETS) at the mitochondrial level, while the energy reserve available for metabolism can be assessed by measuring the total lipid, protein and sugar content. Moreover, the difference between $E_{a}$ and $E_{c}$ represents the net energy budget of the tested organism (De Coen and Janssen, 1997). ETS activity is commonly used as a measure of the potential respiration that could be supported by the enzymatic machinery activity (Freitas et al., 2020a). Organisms under stressful conditions may increase their metabolic capacity to fuel up defence mechanisms. Accompanying this increased metabolism, the expenditure of energy reserves can also increase, leading to a decrease on organism's protein, glycogen and lipids content. Under low stress levels organisms may be able to decrease their metabolism to avoid accumulation of pollutants (example: bivalves close their valves and reduce filtration rate), leading to accumulation of energy reserves. Nevertheless, under high stress conditions organisms may not be able to increase their metabolic capacity although expenditure of energy reserves can continue (Freitas et al., 2020a).

\subsection{Gadolinium effects on freshwater invertebrates}

Effects of Gd in different freshwater invertebrate species are reported in Table 3-supplementary material.

Hanana et al. (2017) investigated the response of the zebra mussel, D. polymorpha, collected in Saint-Laurence river, Quebéc (Canada), to $\mathrm{GdCl}_{3}$ and its pharmaceutical form gadodiamide (Omniscan). Mussels' responses at the transcriptional level of several genes involved in diverse pathways were assessed: SOD and CAT - protection against oxidative stress; MT and GSTs - metal and xenobiotic detoxification; CO1 - mitochondrial alterations; LPO - lipid damage; DNA damage and inflammation. Mussels were exposed to an increasing concentration range of $\mathrm{GdCl}_{3}$ and Omniscan (namely 10, 50, 250 and $1250 \mu \mathrm{g} / \mathrm{L}$ ) for 28 days. At the highest concentration $(1250 \mu \mathrm{g} / \mathrm{L}), \mathrm{GdCl}_{3}$ induced an increase of SOD mRNA levels while decreasing the CAT ones. This caused an upregulation of superoxide (SOD) enzyme and a downregulation of catalase (CAT) enzyme with a consequent production of the ROS $\mathrm{H}_{2} \mathrm{O}_{2}$ (Hanana et al., 2017). Such findings are in accordance with previous studies, which revealed that $\mathrm{GdCl}_{3}$ are responsible for cell apoptosis due to an increase of ROS generation (Liu et al., 2003; Xia et al., 2011; Ye et al., 2011). Moreover, since ROS are known to induce DNA damage and no genotoxic effects have been noticed in the organism after $\mathrm{GdCl}_{3}$ exposure, Hanana et al. (2017) suggested that the modulation in the expression of SOD and CAT genes limited ROS formation as DNA and lipid damages (Hanana et al., 2017). As a consequence of this response, $D$. polymorpha was able to establish an oxidative stress homeostasis, thus preventing any tissue or DNA damages, since no alterations on LPO levels were reported. Another indication of the stress induced by Gd is the modulation of the expression of metallothionein proteins (MT) which are known to play a role in the detoxification of metals and in the ROS scavenging. Nevertheless, the pathways involved in MT gene modulation are not completely clear (Hidalgo et al., 1988; Wong et al., 2004; Hassinen et al., 2011). GSTs gene expression was downregulated at the highest Gd concentration, but the corresponding enzymatic activity was not significantly affected (Hanana et al., 2017). The lack of a noticeable effect on GSTs (glutathione S-transferases) activity could be due to the blocking of common steps in the expression of the detoxifying enzymes by $\mathrm{GdCl}_{3}$ through the competitive inhibition of intracellular calcium influx (Kim and Choi, 1997). This latter study revealed an overexpression of the cytochrome $c$ oxidase (CO1) gene, which caused higher metabolic activity at the ETS level. This consequently led to an overproduction of ATP. Chalghmi et al. (2016) and Karray et al. (2015) proposed that this mechanism might be activated in order to compensate the decreased mitochondrial activity. Therefore, a higher production of ATP molecules could be a cellular strategy to provide enough energy for metal detoxification. The high negative relationship found between COX activity and the Gd level in the tissues suggested that Gd plays also an anti-inflammatory role (Hanana et al., 2017).

Instead, analysis performed employing Omniscan showed that this gadolinium-based contrast agent (GBCA) induced a slight decrease in SOD, CAT and GSTs gene expression, but no correlation has been found with Gd concentration in tissues. In accordance with what had been found for the Gd salt, a positive relationship has been observed between those genes and the mRNA level of the $\mathrm{CO} 1$ gene which was downregulated in organisms exposed to Omniscan. Also in this case, it seems that the activity of $\mathrm{CO} 1$ gene is involved in ROS homeostasis. The downregulation of SOD and CAT instead, could be due to the antioxidant behaviour of Omniscan, which causes the natural mechanisms of the cells to be expressed to a lower extent (Hanana et al., 2017). Higher antioxidant and ROS scavenging activity resulted in reduced physiological deterioration (Yin et al., 2008) and no tissue damage has been observed as revealed by the significant decrease of LPO level. This result was an additional insight on the fact that Omniscan did not promote ROS production and may exhibit antioxidant protective activity in mussels exposed in vivo (Hanana et al., 2017).

Overall, from Hanana et al. (2017) study, it is possible to observe that the chelated Gd does not act as a biologically inert compound as usually thought (Wermuth and Jimenez, 2012). No insight about any possible Gd uptake mechanism have been determined in this study for both $\mathrm{GdCl}_{3}$ and Omniscan compounds. Some of the metabolic correlations caused by Gd pollutants exposure have not been demonstrated by precise data and are only hypothetical pathways suggested by the authors. This is a further demonstration of the lack of information occurring in 
literature about this emerging contaminant. For these reasons, further studies must be performed, to better understand the biochemical pathway of these pollutants in different marine and freshwater organisms.

Perrat et al. (2017) studied the effects of Gd in the form of gadoteric acid (Gd-DOTA - Dotarem) in two freshwater bivalve's species, namely $D$. rostriformis bugensis and C. fluminea organisms, with reference to Gd bioaccumulation. Biochemical markers such as acid phosphatase (ACP), glutathione peroxidase (GPX), lactate dehydrogenase (LDH), LPO, GSTs, ETS, CAT, and the total antioxidant capacity (TAC) have been measured. No changes of the enzymes activities were recorded when compared to controls neither after a 21-day exposure in the presence of 1 or $10 \mu \mathrm{g} / \mathrm{L}$ nor after a 7-day exposure in the presence of $1 \mu \mathrm{g} / \mathrm{L}$ of Gd-DOTA (Perrat et al., 2017). These results are in accordance with those reported by Hanana et al. (2017) and Henriques et al. (2019), whom reported no Gd bioaccumulation in bivalve species when exposed to such low metal concentration. After a 7-day exposure to $10 \mu \mathrm{g} / \mathrm{L}$ of pollutant, a significant increase of GSTs activity compared to controls have been observed in the digestive gland of $D$. rostriformis bugensis while an increase in LPO levels and ETS activity has been observed in the digestive gland of C. fluminea. Such results highlight a transient response in both species, with a faster response in $D$. rostriformis bugensis. The increase on GSTs activity persisted in $D$. rostriformis bugensis after 7 days of exposure, suggesting an early suppression of any effects. In the case of $C$. fluminea, a proof of toxicity (LPO) and an increase in energy expenditure were observed after a 7-day exposure but disappeared after 21 days (Perrat et al., 2017). After 21 days of exposure all biomarkers displayed similar values of those from the control ones, suggesting an efficient response towards Gd toxicity impacts between 7 and 21 days of exposure in the digestive gland of $C$. fluminea. All these responses in the digestive gland of $D$. rostriformis bugensis and $C$. fluminea were supposed to be a consequence of the substantial bioaccumulation in this tissue (Perrat et al., 2017). As for the biochemical activities in the gills, no significant variations were observed during the experiments. These results agree with the previous data of Perrat et al. (2017) which displayed a low bioaccumulation of Gd in the gills tissue. This could mean that the first defence mechanism in the organism acts to expel xenobiotics out of the cell. In this way, the bioaccumulation of Gd is limited, minimizing cell toxicity and therefore biochemical responses (Perrat et al., 2017).

\subsection{Gadolinium effects on marine invertebrates}

Effects of Gd in different marine invertebrate species are reported in Table 3-supplementary material.

In order to establish the variation on the oxidative and energetic balance caused by Gd exposure, laboratory studies have been performed considering different Gd speciation, concentrations, and exposure periods, using a wide variety of invertebrate marine species.

In Henriques et al. (2019), a toxicological assessment of anthropogenic Gd towards the mussel species M. galloprovincialis was performed using different concentrations, namely $15,30,60$ and $120 \mu \mathrm{g} / \mathrm{L}$ of $\mathrm{Gd}_{2} \mathrm{O}_{3}$ (Alfa Aesar Specpure ${ }^{\circledR}$ plasma standard solution). Biological responses were evaluated using biochemical markers. Concerning the energy related biomarkers, mussels exposed to Gd significantly decrease their ETS activity in comparison to non-contaminated ones, reaching a constant value at the highest Gd concentrations (30,60 and $120 \mu \mathrm{g} / \mathrm{L})$. The initial sharp lowering was thought to be a result of a filtration rate reduction to avoid the pollutant accumulation. Since the decrease of ETS was not proportional to the concentration increase, it seems plausible that above certain limits of stress mussels were not able to further decrease their metabolism (Henriques et al., 2019). Gd-exposed mussels enhanced their energy reserves concentrations (glycogen contentGLY and protein content - PROT), in comparison to control organisms, with the highest values found in those exposed to a Gd concentration of $60 \mu \mathrm{g} / \mathrm{L}$. At the highest Gd concentration $(120 \mu \mathrm{g} / \mathrm{L})$, instead, mussels, even with their metabolic capacity reduced, started to employ their energy reserves. This indicates that at higher stress levels GLY and PROT were probably necessary to fuel up defence mechanisms (Henriques et al., 2019). Moreover, the analysis of M. galloprovincialis oxidative stress biomarkers revealed that the activity of SOD was significantly higher in mussels exposed to Gd in comparison to control organisms. Also the activity of CAT increased in those organisms exposed to the metal contaminant comparatively to control mussels. The activity of glutathione peroxidase (GPx) instead, was significantly higher in organisms exposed to 30 and $60 \mu \mathrm{g} / \mathrm{L}$ in relation to the remaining conditions (CTL, 15 and $120 \mu \mathrm{g} / \mathrm{L}$ ) (Henriques et al., 2019). As previously described, when organisms are exposed to pollutants an overproduction of ROS can occur with an associated antioxidant defence response, including the increase of antioxidant enzymes activity. The results obtained in this study indicate that mussels enhanced their antioxidant defence capacity in the presence of Gd, but this response was only effective up to certain limits, since the highest activities were observed at intermediate concentrations (Henriques et al., 2019). Results evidenced that at higher stress levels, which means higher Gd concentration (60 and $120 \mu \mathrm{g} / \mathrm{L}$ ), mussels were not able to proportionally increase their antioxidant capacity, showing enzyme activities similar to control levels (Henriques et al., 2019). Such behaviour may indicate that the overproduction of ROS caused the inhibition of the activity of these enzymes. Another possibility could be that organisms were capable of developing other defence mechanisms that prevent Gd toxicity and there was no need for higher antioxidant defence (Henriques et al., 2019). Any proof regarding this latter hypothesis have been found employing the present biomarkers as indicators of oxidative stress. Concerning the detoxifying mechanisms, GSTs activity was significantly higher in the presence of $\mathrm{Gd}$. As for the antioxidant enzymes, at higher Gd exposure concentrations mussels were no longer able to continue to increase the activity of GSTs along with the increase of Gd concentration. Moreover, LPO levels were significantly higher in mussels exposed to Gd in comparison to uncontaminated mussels. In addition, organisms exposed to $\mathrm{Gd}$ showed significantly lower GSH/ GSSG values comparatively to control values, with no significant differences among Gd exposure conditions (Henriques et al., 2019). These findings clearly demonstrated that Gd induced cellular damage, which was accompanied by loss of redox homeostasis, evidenced by low GSH/GSSG values (Henriques et al., 2019).

Not only bivalve species are influenced by the presence of Gd pollutant in seawater. Martino et al. (2018) investigated the potential alterations caused by dissolved Gd ion to the skeleton formation mechanism in two species of sea urchin, namely Paracentrotus lividus and Heliocidaris tubercolata. Gadolinium Acetate Tetrahydrate (GAT) was employed as a source of Gd and different concentrations have been used: $8130 \mu \mathrm{g} / \mathrm{L}(20 \mu \mathrm{mol} / \mathrm{L})$ for P. lividus; $203 \mu \mathrm{g} / \mathrm{L}(500 \mathrm{nmol} / \mathrm{L})$ and $2000 \mu \mathrm{g} / \mathrm{L}(5 \mu \mathrm{mol} / \mathrm{L})$ for $H$. tuberculata. These species obtain $\mathrm{Ca}^{2+}$ from seawater which is then employed in the construction of the skeleton and spicules. Skeletogenesis is initiated during the early embryonic stage by the so called "primary mesenchyme cells" (PMCs), which have been thought to possess active transporters with high capacity and low affinity, even if they have not yet been identified (Martino et al., 2018). Due to the similarity between $\mathrm{Gd}^{3+}$ and $\mathrm{Ca}^{2+}$ ionic radii, the $\mathrm{Gd}$ cation present in the environment could be uptaken instead of the calcium one, causing malformation of the skeleton (Sherry et al., 2009a, b). The sea urchin P. lividus and the gastropode H. tuberculata showed similar morphological response to $\mathrm{Gd}$. The first impacts of $\mathrm{Gd}$ were visible at the gastrula stage ( $24 \mathrm{~h}$ post fertilization - hpf), at the beginning of skeletogenesis, in which Gd-exposed embryos lacked spicules. This study may indicate that Gd-exposure mainly affected skeleton formation in both species, resulting in a range of abnormalities with a severe inhibition of skeleton growth and patterning in treated embryos (Martino et al., 2018). Some embryos had shorter spicules leading to a reduction of arm length, while others had an asymmetric skeletal pattern. To evaluate the relationship between $\mathrm{Gd}$ exposure, $\mathrm{Ca}^{2+}$ uptake and skeleton growth, $\mathrm{Ca}^{2+}$ and $\mathrm{Gd}^{3+}$ contents were analysed by flame atomic absorption spectrometry (FAAS). From the data obtained it could be noted that control P. lividus embryos showed a 10 -fold higher 
total amount of Ca at $48 \mathrm{hpf}$ than at $24 \mathrm{hpf}$. This means that $\mathrm{Ca}^{2+}$ was employed for the skeleton development. In Gd-treated embryos, a $45.54 \%$ and $78.81 \%$ reduction in the amount of calcium (Ca) compared to controls were observed at $24 \mathrm{hpf}$ and at $48 \mathrm{hpf}$, respectively. The increase in $\mathrm{Ca}^{2+}$ levels during development in Gd-exposed embryos was weak if compared to controls. No Gd was detected in controls while Gd-exposed embryos had $427.8 \pm 60 \mathrm{ng} / \mathrm{mg}$ at $24 \mathrm{hpf}$ and $674.66 \pm$ $49 \mathrm{ng} / \mathrm{mg}$ at $48 \mathrm{hpf}$ (Martino et al., 2018). Gadolinium-exposed $H$. tuberculata embryos instead, showed respectively 80 and $90 \%$ reduction in the amount of Ca at both concentrations, at $24 \mathrm{hpf}$ and at $48 \mathrm{hpf}$, The lowest Gd concentration tested ( $203 \mu \mathrm{g} / \mathrm{L}(500 \mathrm{nmol} / \mathrm{L}))$ was sufficient to block calcium uptake. These results are in accordance with those obtained by Gravina et al. (2018) and Oral et al. (2017), where $\mathrm{GdCl}_{3}$ exposure, in concentration ranging between $26.4 \mu \mathrm{g} / \mathrm{L}\left(10^{-7}\right.$ $\mathrm{mol} / \mathrm{L})$ and $2640 \mu \mathrm{g} / \mathrm{L}\left(10^{-5} \mathrm{~mol} / \mathrm{L}\right)$, resulted in significant damage to embryogenesis and inhibition of fertilization success in P. lividus, Arbacia lixula and Sphaerechinus granularis (Gravina et al., 2018; Oral et al., 2017). Changes on gene expression associated with skeletogenesis were already reported (Martino et al., 2018). These experiments highlighted that Gd has a negative effect on skeleton development and embryogenesis with a similar morphological response in the species tested, implying a similar mechanism underlying these malformations (Martino et al., 2018). The disruption of spicule formation is likely to be due to the action of $\mathrm{Gd}^{3+}$ as a blocker of Ca channels. In fact, being $\mathrm{Gd}^{3+}$ a trivalent ion, it is able to bind with a much higher affinity compared to the divalent calcium cation (Sherry et al., 2009a, b).

\section{Conclusions}

Gadolinium (Gd) has been identified as one of the most commercially exploited rare earth element (REE), which finds it major application in the biomedical field as contrast agent in magnetic resonance imaging after chelating it with either macrocyclic or linear organic molecules.

Even if its complexation almost cancels the toxicity of this metal, many different studies already demonstrated that Gd complexes may cause severe diseases such as nephrogenic systemic fibrosis, mostly in those patients suffering from kidney failure. Nevertheless, its wide employment enhances the risk for this element to be potentially released into the environment, in particular into rivers, lakes and coastal areas through industrial wastewaters or through exhausted devices. For this reason, Gd can be also considered as an indicator for the monitoring of anthropogenic pollution, even if there is no legal limit for REEs in natural waters. However, at the end of 2017, the European Medicines Agency suggested to limit the use of some linear based products and to suspend some linear and macrocyclic compounds used in magnetic resonance imaging.

Despite this fact, very few studies were able to distinguish between geogenic and anthropogenic gadolinium through specific analytical measurements. High Gd values in freshwater have been found in various countries (Germany, France, Turkey, China, Brazil and USA, principally in wastewater treatment plants) effluents, river and coastal waters near hospitals. The total freshwater Gd concentrations ranged between 0.347 and $80 \mu \mathrm{g} / \mathrm{L}$ while Gd seawater ones from 0.36 and $26.9 \mathrm{ng} / \mathrm{L}$ ( 2.3 and $171.4 \mathrm{pmol} / \mathrm{kg}$ ), reaching $409.6 \mathrm{ng} / \mathrm{L}(2605 \mathrm{pmol} / \mathrm{kg})$ at a marine outfall. Even if a lower amount of information is present in literature on Gd contamination in seawater environments, a higher concentration of this REE has been reported in freshwaters.

Concerning literature, 29 articles on the determination of anthropogenic Gd in freshwater and marine environments are available, particularly in European countries (Fig. 3A), with 24 of those (83\%) regarding geogenic and anthropogenic Gd in freshwater, and only 5 papers (17\%) devoted to marine environment. The fact that most of the information on Gd concentrations regards to freshwater systems is mainly due to the high difficulty in determining REEs in seawater, due to the
A

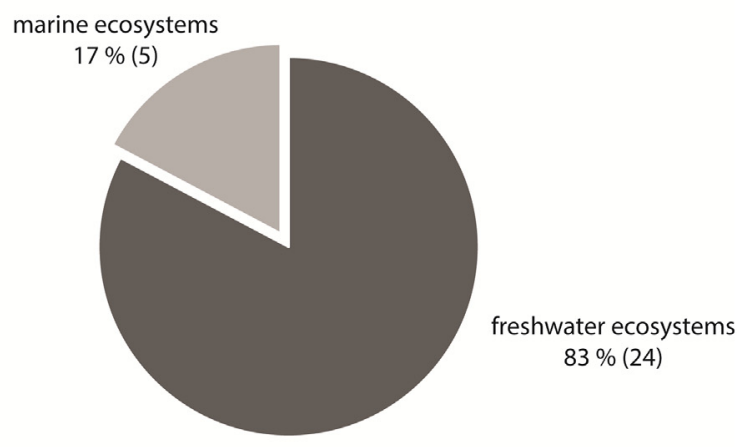

B

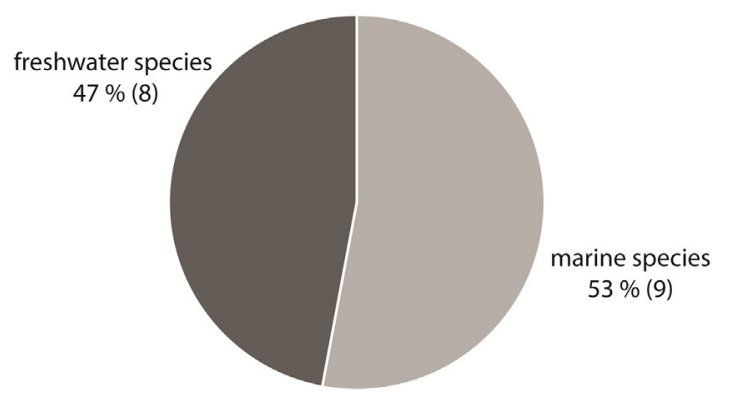

Fig. 3. A: Number and percentage of scientific papers presenting gadolinium concentrations in aquatic ecosystems worldwide (freshwater vs marine ecosystems); B: number and percentage of scientific papers presenting gadolinium concentrations in aquatic invertebrate species (freshwater $v s$ marine species).

remarkable matrix effect and potential spectral interferences during measurement with spectrometers (although sea-FAST methodology greatly overcome this issue, but it is still not a common approach used worldwide). Another obstacle is the difficulty in the differentiation of the background concentration, due to the geogenic processes in water, therefore causing high oscillations in the analytical data obtained. Another aspect that must be pointed out is that the highest Gd anomalies were found in the most industrialized and densely populated areas, which are those hosting the highest number of medical facilities. This is the proof that Gd can be considered as an indicator for the monitoring of anthropogenic pollution.

Nevertheless, still limited information exists regarding the effects induced by Gd in aquatic organisms. Only 17 articles have been found on this topic, with almost the same distribution between freshwater ( 8 articles $-47 \%$ ) and seawater organisms ( 9 articles $-53 \%$ ) (Fig. 3B). In the articles presented in this review different marine and freshwater species were considered, with a predominance of the freshwater bivalve C. fluminea (Fig. 4). From the literature, it is demonstrated that Gd can be bioaccumulated by organisms in a different extent, according to its speciation in water, with concentrations ranging between 0.006 and $0.223 \mu \mathrm{g} / \mathrm{g}$ in freshwater species under field conditions. In fact, chelated gadolinium-based contrast agents used in medical field, display a lower bioavailability compared to naturally occurring Gd, due to their high stability in aquatic environment. In accordance with this evidence, higher bioaccumulation in organisms' tissues and more intense effects on the oxidative homeostasis have been detected employing free $\mathrm{Gd}$ ions, compared to complexed compounds in all the species tested. Biological impacts observed included alterations on gene expression, cellular homeostasis, shell formation, decrease in metabolic activities but also antioxidant effects. 


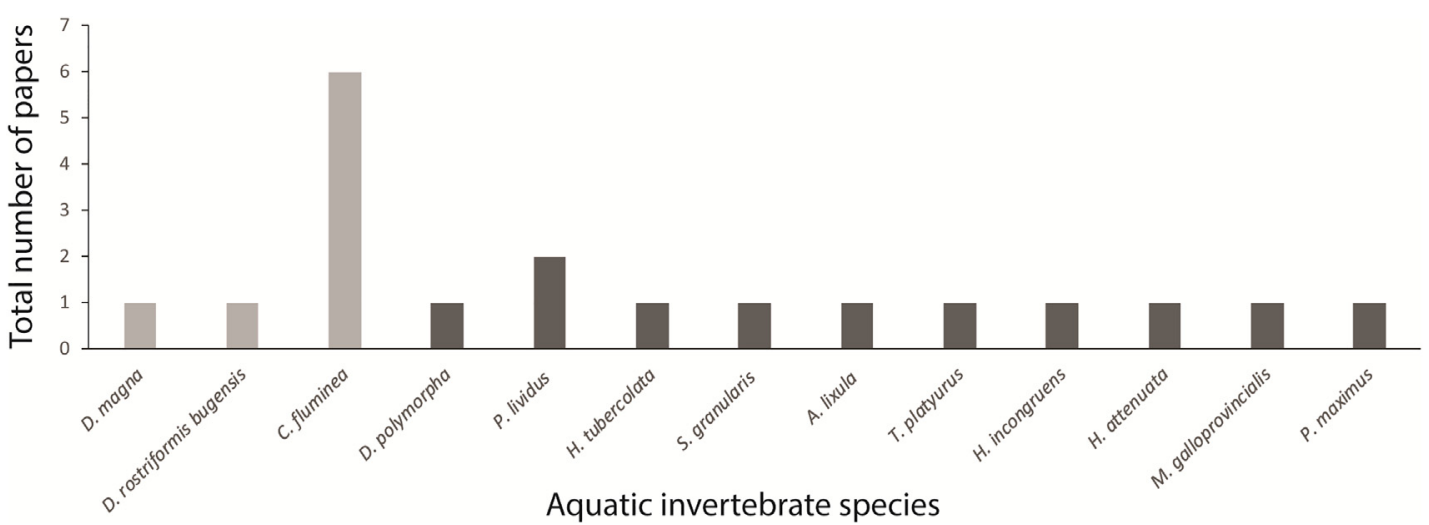

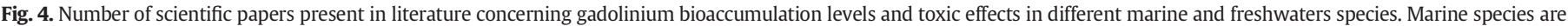
represented with dark gray bars, while freshwater species are represented with light gray bars.

Supplementary data to this article can be found online at https://doi. org/10.1016/j.scitotenv.2021.146273.

\section{CRediT authorship contribution statement}

Giacomo Trapasso: Investigation, Formal analysis, Writing - original draft, Writing - review \& editing. Stefania Chiesa: Supervision, Writing - review \& editing. Rosa Freitas: Supervision, Writing - review \& editing. Eduarda Pereira: Supervision, Writing - review \& editing.

\section{Declaration of competing interest}

The Authors whose names are listed immediately below certify that they have NO affiliations with or involvement in any organization or entity with any financial interest (such as honoraria; educational grants; participation in speakers' bureaus; membership, employment, consultancies, stock ownership, or other equity interest; and expert testimony or patent-licensing arrangements), or non-financial interest (such as personal or professional relationships, affiliations, knowledge or beliefs) in the subject matter or materials discussed in this manuscript.

\section{Acknowledgements}

Giacomo Trapasso conducted this research under the EU (European Community) ERASMUS + program, thanks to an ERASMUS + grant provided by Ca' Foscari University of Venice for his traineeship at the University of Aveiro. Thanks are due to CESAM (UIDB/50017/2020 + UIDP/50017/2020) and REQUIMTE (UIDB/50006/2020). Moreover, authors would like to thank the two anonymous referees who revised the manuscript, for their useful suggestions which greatly improved the paper.

\section{References}

Achard, M., Baudrimont, M., Boudou, A., Bourdineaud, J.P., 2004. Induction of a multixenobiotic resistance protein (MXR) in the Asiatic clam Corbicula fulminea after heavy metal exposure. Aquat. Toxicol. 67 (4), 347-357.

Alkan, A., Alkan, N., Yanar, B., 2020. Investigation of pollution levels originated from anthropogenic gadolinium in Ankara Stream. Environ. Sci. Pollut. Res. 27, 23677-23685.

Alpert, A.J., 1990. Hydrophilic-interaction chromatography for the separation of peptides, nucleic acids and other polar compounds. J. Chromatogr. A 499, 177-196.

Altomare, A.J., Young, N.A., Beazley, M.J., 2020. A preliminary survey of anthropogenic gadolinium in water and sediment of a constructed wetland. J. Environ. Manag. 255.

Ammann, A.A., 2007. Inductively coupled plasma mass spectrometry (ICP-MS): a versatile tool. J. Mass Spectrom. 42, 419-427.

Anastopoulos, I., Bhatnagar, A., Lima, E.C., 2016. Adsorption of rare earth metals: a review of recent literature. J. Mol. Liq. 221, 954-962.

Atwood, D.A., 2012. The Rare Earth Elements. Fundamentals and Applications. John Wiley \& Sons, West Sussex.

Augusto, F., Hantao, L.W., Mogollón, G.S., Braga, S.C.G., 2013. New materials and trends in sorbents for solid-phase extraction. Trends Anal. Chem. 43, 14-23.
Australian Industry Commission, 1995. New and Advanced Materials. Australian Government Publishing Service, Melbourne, Australia.

Balusamy, B., Taștan, B.E., Ergen, S.F., Uyarbe, T., Tekinay, T., 2015. Toxicity of lanthanum oxide $\left(\mathrm{La}_{2} \mathrm{O}_{3}\right)$ nanoparticles in aquatic environments. Environ Sci Process Impacts $17,1265-1270$.

Barber, L.B., Loyo-Rosales, J.E., Rice, C.P., Minarik, T.A., Oskouie, A.K., 2015. Endocrine disrupting alkylphenolic chemicals and other contaminants in wastewater treatment plant effluents, urban streams, and fish in the Great Lakes and Upper Mississippi River regions. Sci. Total Environ. 517, 195-206.

Bau, M., Dulski, P., 1996. Anthropogenic origin of positive gadolinium anomalies in river waters. Earth Planet. Sci. Lett. 143 (1-4), 245-255.

Bellin, M., Van Der Molen, A.J., 2008. Extracellular gadolinium-based contrast media: an overview. Eur. J. Radiol. 66, 160-167.

Birka, M., Roscher, J., Holtkamp, M., Sperling, M., Karst, U., 2016a. Investigating the stability of gadolinium based contrast agents towards UV radiation. Water Res. 91, 244-250.

Birka, M., Wehe, C.A., Hachmoller, O., Sperling, M., 2016b. Tracing gadolinium-based contrast agents from surface water to drinking water by means of speciation analysis, J. Chromatogr. A 1440, 105-111

Blaise, C., Gagne, F., Harvood, M., Quinn, B., Hanana, H., 2018. Ecotoxicity responses of the freshwater cnidarian Hydra attenuata to 11 rare earth elements. Ecotoxicol. Environ. Saf. 163, 486-491.

Blinova, I., Lukjanova, A., Muna, M., Vija, H., Kahru, A., 2018. Evaluation of the potential hazard of lanthanides to freshwater microcrustaceans. Sci. Total Environ. 642, 1100-1107.

Braun, M., Zavanyi, G., Laczovics, A., Berényi, E., Szabó, S., 2017. Can aquatic macrophytes be biofilters for gadolinium based contrasting agents? Water Res. 135, 104-111.

Byrne, R.H., Liu, X.W., Schijf, J., 1996. The influence of phosphate coprecipitation on rare earth distributions in natural waters. Geochim. Cosmochim. Acta 60, 3341-3346.

Chakhmouradlan, A.R., Wall, F., 2012. Rare earth elements: minerals, mines, magnets. Elements 8, 333-340.

Chalghmi, H., Bourdineaud, J.P., Haouas, Z., Gourves, P.Y., Zrafi, I., Saidane-Mosbahi, D., 2016. Transcriptomic, biochemical, and histopathological responses of the clam ruditapes decussatus from a metal-contaminated Tunis lagoon. Arch. Environ. Contam. Toxicol. 70, 241-256.

Chiesa, S., Azzurro, E., Bernardi, G., 2019. The genetics and genomics of marine fish invasions: a global review. Rev. Fish Biol. Fish. 29, 837-859.

Clases, D., Sperling, M., Karst, U., 2018. Analysis on metal-based contrast agents in medicine and the environment. Trends Anal. Chem. 104, 135-147.

Cyris, M., 2013. Behavior of Gadolinium-based Diagnostics in Water Treatment PhD thesis.

Dan'kov, A.M., Tishin, V.K., Pecharsky, Gschneidner Jr., K.A., 1998. Magnetic phase transitions and the magnetothermal properties of gadolinium. Phys. Rev. 57 (6), 3478-3490.

De Campos, F., Enzweiler, J., 2016. Anthropogenic gadolinium anomalies and rare earth elements in the water of Atibaia River and Anhumas Creek, Southeast Brazil. Environ. Monit. Assess. 188 (281).

De Coen, W.M., Janssen, C.R., 1997. The use of biomarkers in Daphnia magna toxicity testing. IV. Cellular Energy Allocation: a new methodology to assess the energy budget of toxicant-stressed Daphnia populations. J. Aquat. Ecosyst. Stress. Recover. 6, 43-55.

Djingova, R., Ivanova, J., 2002. Determination of rare earth elements in soils and sediments by inductively coupled plasma atomic emission spectrometry after cationexchange separation. Talanta 57 (3), 821-829.

Duarte, B., Caçador, I., 2020. Ecotoxicology of Marine Organisms. CRC Press.

Emsley, J., 2011. Nature's Building Blocks: An A-Z Guide to the Elements. Oxford University Press, New York, NY, USA.

Fisher, A., Kara, D., 2016. Determination of rare earth elements in natural water samples a review of sample separation, preconcentration and direct methodologies. Anal. Chim. Acta 935, 1-29.

Frame, E.M.S., Uzgiris, E.E., 1998. Gadolinium determination in tissue samples by inductively coupled plasma mass spectrometry and inductively coupled plasma atomic emission spectrometry in evaluation of the action of magnetic resonance imaging contrast agents. Analyst 123, 675-679. 
Freitas, R., Cardoso, C.E.D., Costa, S., Morais, T., Moleiro, P., Lima, A.F.D., Soares, M., Figueiredo, S., Agueda, T.L., Rocha, P., Amador, G., Soares, A.M.V.M., Pereira, E., 2020a. New insights on the impacts of e-waste towards marine bivalves: The case of the rare earth element Dysprosium. Environ. Pollut. 260, 113859.

Freitas, R., Costa, S., Cardoso, C.E.D., Morais, T., Moleiro, P., Matias, A.C., Pereira, A.F., Machado, J., Correia, B., Pinheiro, D., Rodrigues, A., Colónia, J., Soares, A.M.V.M., Pereira, E., 2020b. Toxicological effects of the rare earth element neodymium in Mytilus galloprovincialis. Chemosphere 244, 125457.

Fujiwara, K., Matsumoto, Y., Kawakami, H., Aoki, M., Tuzuki, M., 2008. Evaluation of metal toxicity in Chlorella kessleri from the perspective of the periodic table. Bull. Chem. Soc. Jpn. 81 (4), 478-488.

Gama, M.R., Da Costa, Silva R.G., Collins, C.H., Bottoli, C.B.G., 2012. Hydrophilic interaction chromatography. Trends Anal. Chem. 37, 48-60

Gibby, A.W., Gibby, A.K., Gibby, W.A., 2004. Comparison of Gd DTPA-BMA (Omniscan) versus Gd HP-DO3A (ProHance) Retention in Human Bone Tissue by Inductively Coupled Plasma Atomic Emission Spectroscopy. Investigative Radiology 39 (3), 138-142.

González, V., Vignati, D.A.L., Pons, M., Montarges-Pelletier, E., Bojic, C., Giamberini, L., 2015. Lanthanide ecotoxicity: first attempt to measure environmental risk for aquatic organisms. Environ. Pollut. 199, 139-147.

Goodenough, K.M., Schilling, J., Jonsson, E., Kalvig, P., Charles, N., Tuduri, J., Deady, E.A., Sadeghi, M., Schiellerup, H., Müller, A., Bertrand, G., Arvanitidis, N., Eliopoulos, D.G., Shaw, R.A., Thrane, K., Keulen, N., 2016. Europe's rare earth element resource potential: an overview of REE metallogenetic provinces and their geodynamic setting. Ore Geol. Rev. 72, 838-856.

Gravina, M., Pagano, G., Oral, R., Giuda, M., Toscanesi, M., Siciliano, A., Di Nunzio, A., Buric, P., Lyons, D.M., Thomas, P.J., Trifuoggi, M., 2018. Heavy rare earth elements affect Sphaerechinus granularis sea urchin early life stages by multiple toxicity endpoints. Bull. Environ. Contam. Toxicol. 100, 641-646.

Greenwood, A., Norman, N., Earnshaw, A., 1997. Chemistry of the Elements. 2nd ed. Butterworth-Heinemann.

Grobenski, Z., 1978. Applications of furnace AAS for the determination of the lanthanoids and the study of related phenomena. Anal. Chem. 289, 337-345.

Grobner, T., 2005. Gadolinium: a specific trigger for the development of nephrogenic fibrosing dermopathy and nephrogenic systemic fibrosis? Nephrol. Dial. Transplant. 21, 1104-1108.

Grobner, T., Prischl, F.C., 2007. Gadolinium and nephrogenic systemic fibrosis. Kidney Int. 72 (3), 260-264.

Gwenzi, W., Mangori, L., Danha, C., Chaukura, N., Dunjana, N., Sanganyadoe, E., 2018. Sources, behaviour, and environmental and human health risks of high technology rare earth elements as emerging contaminants. Sci. Total Environ. 636, 299-313.

Hall, G.E.M., Vaive, J.E., Beer, R., Hoashi, M., 1996. Selective leaches revisited, with emphasis on the amorphous Fe oxyhydroxide phase extraction. J. Geochem. Explor. 56 (1), $59-78$.

Hanana, H., Turcotte, P., André, C., Gagnon, C., Gagné, F., 2017. Comparative study of the effects of gadolinium chloride and gadolinium e based magnetic resonance imaging contrast agent on freshwater mussel, Dreissena polymorpha. Chemosphere 181, 197-207.

Hao, S., Xiaorong, W., Liansheng, W., Lemei, D., Zhong, L., Yijun, C., 1997. Bioconcentration of Rare Earth Elements lanthanum, gadolinium and yttrium in algae (Chlorella Vulgarize Beijerinck): influence of chemical species. Chemosphere 34 (8), 1753-1760.

Hassinen, V.H., Tervahauta, A.I., Schat, H., Kärenlampi, S.O., 2011. Plant metallothioneins metal chelators with ROS scavenging activity? Plant Biol. 13, 225-232.

Hathorne, E.C., Haley, B., Stichel, T., Grasse, P., Zieringer, M., Frank, M., 2012. Online preconcentration ICP-MS analysis of rare earth elements in seawater. Geochem. Geophys. Geosyst. 13, 1-12.

Hatje, V., Bruland, K.W., Flegal, A.R., 2016. Increases in anthropogenic gadolinium anomalies and rare earth element concentrations in San Francisco Bay over a 20 year record. Environ. Sci. Technology 50, 4159-4168.

He, M.L., Rambeck, W.A., 2000. Rare earth elements-a new generation of of growth promoters for pigs? Arch. Anim. Nutr. 53 (4), 323-334.

Hemström, P., Irgum, K., 2006. Hydrophilic interaction chromatography. J. Sep. Sci. 29 (12), 1784-1821.

Henriques, B., Coppola, F., Monteiro, R., Pinto, J., Viana, T., Pretti, C., Soares, A., Freitas, R., Pereira, E., 2019. Toxicological assessment of anthropogenic gadolinium in seawater: biochemical effects in mussels Mytilus galloprovincialis. Sci. Total Environ. 664, 626-634.

Hidalgo, J., Campmany, L., Borras, M., Garvey, J.S., Armario, A., 1988. Metallothioneins response to stress in rats: role in free radical scavenging. Am. J. Physiol.-Endocrinol. Metab. 255 (4)

Hron, T., Kuba, J., Cingros, F., 2009. Magneto - caloric effect in gadolinium. 32nd International Spring Seminar on Electronics Technology, Brno, pp. 1-4.

Idee, J.M., Port, M., Raynal, I., Schaefer, M., Le Greneur, S., Corot, C., 2006. Clinical and biological consequences of transmetallation induced by contrast agents for magnetic resonance imaging: a review. Fundam. Clin. Pharmacol. 20, 563-576.

IUPAC, 2005. Nomenclature of Inorganic Chemistry. IUPAC Recommendations 2005 ("Red Book"). RSC Publishing, Cambridge (UK) 0-85404-438-8.

Joonas, E., Aruoja, V., Olli, K., Syvertsen-Wiig, G., Vija, H., Kahruad, A., 2017. Potency of (doped) rare earth oxide particles and their constituent metals to inhibit algal growth and induce direct toxic effects. Sci. Total Environ. 593-594, 478-486.

Kálmán, F.K., Woods, M., Caravan, P., Jurek, P., Spiller, M., Tircsó, G., Király, R., Brücher, E., Sherry, A.D., 2007. Potentiometric and relaxometric properties of a gadolinium-based MRI contrast agent for sensing tissue $\mathrm{pH}$. Inorg. Chem. 46, 5260-5270.

Kamenopoulos, S.N., Shields, D., Agioutantis, Z., 2016. Sustainable development criteria and indicators for the assessment of rare earth element mining projects. Rare Earths Industry.
Karray, S., Tastard, E., Moreau, B., Delahaut, L., Geffard, A., Guillon, E., Denis, F., HamzaChaffai, A., Chénais, B., Marchand, J., 2015. Transcriptional response of stressregulated genes to industrial effluent exposure in the cockle Cerastoderma glaucum. Environ. Sci. Pollut. Res. 22, 17303-17316.

Khan, A.M., Yusoff, I., Abu Bakar, N.K., Abu Bakar, A.F., Alias, Y., 2016. Assessing of anthropogenic levels, speciation, and potential mobility of rare earth elements (REEs) in extin mining area. Environ. Sci. Pollut. Res. 23, 25039-25055.

Khan, A.M., Behkami, S., Yusoff, I., Md Zain, S.B., Bakar, N.K.A., Bakar, A.F.A., Alias, Y., 2017. Geochemical characteristics of rare earth elements in different types of soil: a chemometric approach. Chemosphere 184, 673-678.

Khorasanipour, M., Rashidi, S., 2020. Geochemical fractionation pattern and environmental behaviour of rare earth elements (REEs) in mine wastes and mining contaminated sediments; Sarcheshmeh mine, SE of Iran. J. Geochem. Explor. 210, 106450.

Kim, S.G., Choi, S.H., 1997. Gadolinium chloride inhibition of rat hepatic microsomal epoxide hydrolase and glutathione S-transferase gene expression. Drug Metab. Dispos. 25 1416-1423.

Kimura, J., Ishiguchi, T., Matsuda, J., Ohno, R., Nakamura, A., Kamei, S., Ohno, K. Kawamura, T., Murata, K., 2005. Radiation Medicine. 23 p. 322.

Klinger, J.M., 2015. A historical geography of rare earth elements: from discovery to the atomic age. Extract. Indust. Soc. 2, 572-580.

Klockenkämper, R., Von Bohlen, A., 2015. Total Reflection X-Ray Fluorescence Analysis and Related Methods. John Wiley \& Sons Inc.

Kulaksız, S., Bau, M., 2007. Contrasting behaviour of anthropogenic gadolinium and natural rare earth elements in estuaries and the gadolinium input into the North Sea. Earth Planet. Sci. Lett. 260 (1-2), 361-371.

Kulaksız, S., Bau, M., 2011. Rare earth elements in the Rhine River, Germany: first case of anthropogenic lanthanum as a dissolved microcontaminant in the hydrosphere. Environ. Int. 37, 973-979.

Kulaksız, S., Bau, M., 2013. Anthropogenic dissolved and colloid/nanoparticle-bound samarium, lanthanum and gadolinium in the Rhine River and the impending destruction of the natural rare earth element distribution in rivers. Earth Planet. Sci. Lett. 362, 43-50.

Kummerer, K., Helmers, E., 2000. Hospital effluents as a source of gadolinium in the aquatic environment. Environ. Sci. Technol. 34 (4), 573-577.

Laurent, S., Elst, L.V., Muller, R.N., 2006. Comparative study of the physicochemical properties of six clinical low molecular weight gadolinium contrast agents. Contr. Med. Mol. Imaging 1, 128-137.

Laurent, S., Vander, Elsta L., Henoumonta, C., Mullera, R.N., 2010. How to measure the transmetalation of a gadolinium complex. Contr. Med. Mol. Imaging 5, 305-308.

Le Goff, S., Barrat, J., Chauvaud, L., Paulet, Y., Gueguen, B., Salem, D.B., 2019. Compoundspecific recording of gadolinium pollution in coastal waters by great scallop. Sci. Rep. Nat. 9, 8015

Li, X., Zhang, F., Zhao, D., 2013. Highly efficient lanthanide upconverting nanomaterials: progresses and challenges. Nano Today 8, 643-676.

Lian, L., D’Haese, P.C., Lamberts, L.V., Van de Vyver, F.L., De Broe, M.E., 1991. Determination of gadolinium in biological materials using graphite furnace atomic absorption spectrometry with a tantalum boat after solvent extraction. Anal. Chem. 63, 423-427.

Liang, P., Liu, Y., Guo, L., 2005. Determination of trace rare earth elements by inductively coupled plasma atomic emission spectrometry after preconcentration with multiwalled carbon nanotubes. Spectrochim. Acta B At. Spectrosc. 60, 125-129.

Lindner, U., Lingott, J., Richter, S., Jakubowski, N., Panne, U., 2013. Speciation of gadolinium in surface water samples and plants by hydrophilic interaction chromatography hyphenated with inductively coupled plasma mass spectrometry. Anal. Bioanal. Chem. $405,1865-1873$

Liu, H., Yuan, L., Yang, X., Wang, K., 2003. La3+, Gd3+ and Yb3+ induced changes in mitochondrial structure, membrane permeability, cytochrome c release and intracellular ROS level. Chem. Biol. Interact. 146, 27-37.

Mancheri, N.A., Sprecher, B., Bailey, G., Ge, J., Tukker, A., 2019. Effect of Chinese policies on rare earth supply chain resilience. Resour. Conserv. Recycl. 142, 101-112.

Marckmann, P., 2006. Nephrogenic systemic fibrosis: suspected causative role of gadodiamide used for contrast-enhanced magnetic resonance imaging. J. Am. Soc. Nephrol. 17, 2359-2362.

Markich, S.J., Jeffree, R.A., Burke, P.T., 2002. Freshwater bivalve shells as archival indicators of metal pollution from a copper-uranium mine in tropical Northern Australia. J. Am. Chem. Soc. 36 (5), 821-832.

Martino, C., Costa, C., Roccheri, M.C., Koop, D., Scudiero, R., Byrne, M., 2018. Gadolinium perturbs expression of skeletogenic genes, calcium uptake and larval development in phylogenetically distant sea urchin species. Aquat. Toxicol. 194, 57-66.

Massari, S., Ruberti, M., 2013. Rare earth elements as critical raw materials: focus on international markets and future strategies. Resour. Pol. 38, 36-43.

Mendichovszky, I.A., Marks, S.D., Simcock, C.M., Olsen, Ø.E., 2008. Gadolinium and nephrogenic systemic fibrosis: time to tighten practice. Pediatr. Radiol. 38, 489-496.

Merschel, G., Bau, M., 2015. Rare earth elements in the aragonitic shell of freshwater mussel Corbicula fluminea and the bioavailability of anthropogenic lanthanum, samarium and gadolinium in river water. Sci. Total Environ. 533, 91-101.

Mestre, N.C., Sousa, V.S., Rocha, T.L., Bebianno, M.J., 2019. Ecotoxicity of rare earths in the marine mussel Mytilus galloprovincialis and a preliminary approach to assess environmental risk. Ecotoxicology 28, 294-301.

Migaszewski, Z.M., Gałuszka, A., 2015. The characteristics, occurrence, and geochemical behavior of rare earth elements in the environment: a review. Crit. Rev. Environ. Sci. Technol. 45, 429-471.

Möller, P., Morteani, G., Dulski, P., 2003. Anomalous gadolinium, cerium, and yttrium contents in the Adige and Isar coriver waters and in the water of their tributaries (Provinces Trento and Bolzano/Bozen, NE Italy). Acta Hydrochim. Hydrobiol. 31 (3), 225-239. 
Moreira, A., Henriques, B., Leite, C., Libralato, G., Pereira, E., Freitas, R., 2020. Potential impacts of lanthanum and yttrium through embryotoxicity assays with Crassostrea gigas. Ecol. Indic. 108, 105687.

Nakamura, Y., Tsumura, Y., Tonogai, Y., Shibata, T., Ito, Y., 1997. Differences in behavior among the chlorides of seven rare earth elements administered intravenously to rats. Fundam. Appl. Toxicol. 37, 106-116.

Normann, P.T., Hustvedt, S.O., Storflor, H., Hals, P.A., 1995. Preclinical safety and pharmacokinetic profile of gadodiamide injection. Clin. MRI 5, 95-101.

OECD, 2015. Health at a Glance 2015: OECD Indicators Paris.

Oral, R., Pagano, G., Siciliano, A., Gravina, M., Palumbo, A., Castellano, I., Migliaccio, O., Thomas, P.J., Guida, M., Tommasi, F., Trifuoggi, M., 2017. Heavy rare earth elements affect early life stages in Paracentrotus lividus and Arbacia lixula sea urchins. Environ. Res. 154, 240-246.

Pagano, G., Aliberti, F., Giuda, M., Oral, R., Siciliano, A., Trifuoggi, M., Tommasi, F., 2015. Rare earth elements in human and animal health: state of art and research priorities. Environ. Res. 142, 215-220.

Parant, M., Perrat, E., Wagner, P., Rosin, C., Py, J., Cossu-Leguille, C., 2018. Variations of anthropogenic gadolinium in rivers close to waste water treatment plant discharges. Environ. Sci. Pollut. Res. 25 (36).

Pastorino, P., Brizio, P., Abete, M.C., Bertoli, M., Oss Noser, A.G., Piazza, G., Prearo, M., Elia, A.C., Pizzul, E., Squadrone, S., 2020. Macrobenthic invertebrates as tracers of rare earth elements in freshwater watercourses. Sci. Total Environ. 698.

Pecharsky, V.K., Gschneidner Jr., K.A., 2019. Rare-Earth Element. Encyclopædia Britannica, Inc.

Pedreira, R.M.A., Pahnke, K., Böning, P., Hatje, V., 2018. Tracking hospital effluent-derived gadolinium in Atlantic coastal waters off Brazil. Water Res. 145, 62-72.

Pereto, C., Coynel, A., Lerat-Hardy, A., Gourves, P.Y., Schäfer, J., Baudrimont, M., 2020. Corbicula fluminea: a sentinel species for urban Rare Earth Element origin. Sci. Total Environ. 732.

Perrat, E., Parant, M., Py, J.S., Rosin, C., Cossu-Leguille, C., 2017. Bioaccumulation of gadolinium in freshwater bivalves. Environ. Sci. Pollut. Res. 24, 12405-12415.

Pinto, J., Costa, M., Leite, C., Borges, C., Coppola, F., Henriques, B., Monteiro, R., Russo, T., Di Cosmo, A., Soares, A.M.V.M., Polese, G., Pereira, E., Freitas, R., 2019. Ecotoxicological effects of lanthanum in Mytillus galloprovincialis: biochemical and histopathological impacts. Aquat. Toxicol. 211, 181-192.

Pramanik, S., Das, P., 2019. Nanomaterials and Polymers Nanocomposites. Elsevier, pp. 91-121.

Pratas, J., Favas, P.J.C., Varun, M., D’Souza, R., Paul, M.S., 2017. Distribution of rare earth elements, thorium and uranium in streams and aquatic mosses of Central Portugal. Environ. Earth Sci. 76, 156

Pyrzynska, K., Kubiak, A., Wysocka, I., 2016. Application of solid phase extraction procedures for rare earth elements determination in environmental samples. Talanta $154,15-22$.

Rabiet, M., Brissaud, F., Seidel, J.L., Pistre, S., Elbaz-Poulichet, F., 2009. Positive gadolinium anomalies in wastewater treatment plant effluents and aquatic environment in the Hérault watershed (South France). Chemosphere 75 (8), 1057-1064.

Raju, C.S.K., Cossmer, A., Scharf, H., Panne, U., Lück, D., 2010. Speciation of gadolinium based MRI contrast agents in environmental water samples using hydrophilic interaction chromatography hyphenated with inductively coupled plasma mass spectrometry. J. Anal. At. Spectrom. 25, 55-61.

Ramalho, J., Semelka, R.C., Ramalho, M., Nunes, R.H., AlObaidy, M., Castillo, M., 2016. Gadolinium-based contrast agents accumulation and toxicity: an update. Am. J. Neuroradiol. 37, 1192-1198.

Regoli, F., Giuliani, M.E., 2014. Oxidative pathways of chemical toxicity and oxidative stress biomarkers in marine organisms. Mar. Environ. Res. 93, 106-117.

Rogowska, J., Olkowska, E., Ratajczyk, W., Wolska, L., 2018. Gadolinium as a new emerging contaminant of aquatic environments. Environ. Toxicol. Chem. 37, 1523-1534.

Rousseau, R.M., 2006. Corrections for matrix effects in X-ray fluorescence analysis-a tutorial. Spectrochim. Acta B At. Spectrosc. 61, 759-777.

Runge, V.M., 2018. Dechelation (Transmetalation): consequences and safety concerns with the linear gadolinium-based contrast agents, in view of recent Health care rulings by the EMA (Europe), FDA (United States), and PMDA (Japan). Investig. Radiol. 53 (10), 571-578.

Rzymski, P., Klimaszyk, P., Niedzielski, P., Marszelewski, W., Borowiak, D., Nowiński, K., Baikenzheyeva, A., Kurmanbayev, R., Aladin, N., 2019. Pollution with trace elements and rare-earth metals in the lower course of Syr Darya River and Small Aral Sea, Kazakhstan. Chemosphere 234, 81-88.

Schijf, J., Christy, I.J., 2018. Effect of Mg and Ca on the stability of the MRI contrast agent Gd-DTPA in seawater. Front. Mar. Sci. 5, 111.

Shen, L., Wu, N., Zhong, S., Gao, L., 2017. Overview on China's rare earth industry restructuring and regulation reforms. J. Resour. Ecol. 8, 2013-2022.

Sherry, A.D., Caravan, P., Lenkinski, R.E., 2009a. Primer on gadolinium chemistry. J. Magn. Reson. Imaging 30, 1240-1248.

Sherry, A.D., Caravan, P., Lenkinski, R.E., 2009b. Primer on gadolinium chemistry. J. Magn. Reson. Imaging 30, 1240-1248.
Silva, C.D., Santana, G.P., Paz, S.P.A., 2020. Determination of La, Ce, Nd, Sm, and Gd in mineral waste from cassiterite beneficiation by wavelength-dispersive X-ray fluorescence spectrometry. Talanta 206, 120254.

Sneller, F.E.C., Kalf, D.F., Weltje, L., Van Wezel, A.P., 2000. Maximum permissible concentrations and negligible concentrations for rare earth elements (REEs). Report No. RIVM 601501011. National Institute of Public Health and the Environment, Bilthoven.

Telgmann, L., Holtkamp, M., Künnemeyer, J., Gelhard, C., Hartmann, M., Klose, A., Sperling M., Karst, U., 2011. Simple and rapid quantification of gadolinium in urine and blood plasma samples by means of total reflection X-ray fluorescence (TXRF). Metallomics 3, 1035-1040.

Telgmann, L., Sperling, M., Karst, U., 2013. Determination of gadolinium-based MRI contrast agents in biological and environmental samples: a review. Anal. Chim. Acta 764, 1-16.

Thomsen, H.S., Marckmann, P., 2008. Extracellular Gd-CA: differences in presence of NSF. Eur. J. Radiol. 66 (2), 180-183.

US-EPA, 2012. Rare Earth Elements: A Review of Production, Processing, Recycling, and Associated Environmental Issues. United States Environmental Protection Agency, Cincinnati OH EPA/600/R-12/572.

USGS, 2010. Mineral Commodity Summaries (Rare Earth). U.S. Geological Survey.

USGS, 2016. Mineral Commodity Summaries (Rare Earth). U.S. Geological Survey.

Verplanck, P.L., Taylor, H.E., Nordstrom, D.K., Barber, L.B., 2005. Aqueous stability of gadolinium in surface waters receiving sewage treatment plant effluent, Boulder Creek, Colorado. Environ. Sci. Technol. 39, 6923-6929.

Wang, X., Jin, T., Comblin, V., Lopez-Mut, A., Merciny, E., Desreux, J.F., 1992. A kinetic investigation of the lanthanide DOTA chelates. Stability and rates of formation and of dissociation of a macrocyclic gadolinium(III) polyaza polycarboxylic MRI contrast agent. Inorg. Chem. 31, 1095-1099.

Wang, Z., Yin, L., Xiang, H., Qin, X., Wang, S., 2019. Accumulation patterns and speciesspecific characteristics of yttrium and rare earth elements (YREEs) in biological matrices from Maluan Bay, China: implications for biomonitoring. Environ. Res. 179.

Weltje, L., Heidenreich, H., Zhu, W., Wolterbeek, H.Th., Korhammer, S., De Goeij, J.J.M., Markert, B., 2002. Lanthanide concentrations in freshwater plants and molluscs, related to those in surface water, pore water and sediment. A case study in The Netherlands. Sci. Total Environ. 286 (1-3), 191-214.

Wermuth, P.J., Jimenez, S.A., 2012. Gadolinium compounds signaling through TLR 4 and TLR 7 in normal human macrophages: establishment of a proinflammatory phenotype and implications for the pathogenesis of nephrogenic systemic fibrosis. J. Immunol. 189 (1), 318-327.

Wong, H.L., Sakamoto, T., Kawasaki, T., Umemura, K., Shimamoto, K., 2004. Downregulation of metallothionein, a reactive oxygen scavenger, by the small GTPase OsRac1 in rice. Plant Physiol. 135, 1447-1456.

Xia, Q., Feng, X., Huang, H., Du, L., Yang, X., Wang, K., 2011. Gadolinium-induced oxidative stress triggers endoplasmic reticulum stress in rat cortical neurons. J. Neurochem. 117, 38-47.

Xu, N., Morgan, B., Rate, A.W., 2018. From source to sink: rare-earth elements trace the legacy of sulfuric dredge spoils on estuarine sediments. Sci. Total Environ. 637-638, 1537-1549.

Xun, W., Shi, L., Hou, G., Zhou, H., Yue, W., Zhang, C., Ren, Y., 2014. Effect of rare earth elements on feed digestibility, rumen fermentation, and purine derivetives in sheep. Ital. J. Anim. Sci. 13 (2), 357-362.

Ye, L., Shi, Z., Liu, H., Yang, X., Wang, K., 2011. Gadolinium induced apoptosis of human embryo liver L02 cell line by ROS-mediated AIF pathway. J. Rare Earths 29 (2), $178-184$.

Yessoufou, A., Ifon, B.E., Suanon, F., Dimon, B., Sun, Q., Dedjiho, C.A., Mama, D., Yu, C., 2017. Environ. Monit. Assess. 189, 625

Yin, J.J., Lao, F., Meng, J., Fu, P.P., Zhao, Y., Xing, G., Gao, X., Sun, B., Wang, P.C., Chen, C., Liang, X.J., 2008. Inhibition of tumor growth by endohedral metallofullerenol nanoparticles optimized as reactive oxygen species scavenger. Mol. Pharmacol. 74, 1132-1140.

Zepf, V., 2015. An overview of the usefulness and strategic value of rare earth metals. Rare Earths Industry: Technological, Economic, and Environmental Implications. Elsevier, pp. 3-17.

Zhang, Y., Wei, W., Das, G.K., Tan, T.T.Y., 2014. Engineering lanthanide-based materials for nanomedicine. J. Photochem. Photobiol. 20, 71-96.

Zhang, P., Zhang, L., Tang, J., 2015. Lanthanide single molecule magnets: progress and perspective. Dalton Trans. 44, 3923-3929.

Zhao, F., Cong, Z., Sun, H., Ren, D., 2007. The geochemistry of rare earth elements (REEs) in acid mine drainage from the Sitai coal mine Shanxi Province, North Cina. Int. J. Coal Geol. 70 (1-3), 184-192.

Zhou, G.H., Sun, B.B., Liu, Z.Y., Wei, H.L., Zeng, D.M., Zhang, B.M., 2012. Geochemical feature of rare earth elements in major rivers of eastern China. Geosciences 26, 1028-1104.

Zhou, B., Li, Z., Zhao, Y., Zhang, C., Wei, Y., 2016. Rare earth elements supply vs. clean energy technologies: new problems to be solve. Gospod. Surow. Miner. 32, 29-44. 